\title{
Assessing the immediate impact of COVID-19 lockdown on the air quality of Kolkata and Howrah, West Bengal, India
}

\author{
Mohan Sarkar ${ }^{1} \cdot$ Anupam Das $^{2} \cdot$ Sutapa Mukhopadhyay ${ }^{1}$
}

Received: 22 June 2020 / Accepted: 12 September 2020 / Published online: 22 September 2020

(c) Springer Nature B.V. 2020

\begin{abstract}
The worldwide spread of COVID-19 caused a nationwide lockdown in India from 24 March 2020 and was further extended up to 3 May 2020 to break off the transmission of novel Coronavirus. The study is designed to assess the changes in air quality from the prelockdown period to the during lockdown period in Kolkata and Howrah municipal corporation, West Bengal, India. GIS-based techniques include the spatial and temporal distribution of pollutants using interpolation method, and on the other hand, statistical methods like analysis of variance (ANOVA) was applied to determine the mean differences two phases and correlation matrix helps to understand the changing association of the pollutants in pre- and during lockdown phases. Significant correlations have been found among the pollutants, ANOVA (Two-Way) has shown the significant mean difference of NAQI between the two phases, $F(1,611)=465.723, p<0.0001$; pairwise comparison for Ballygunge has shown the highest mean difference 108.194 at $p<0.0001$ significant level between lockdown and pre-lockdown phase. Significant positive correlation has been found between $\mathrm{PM}_{2.5}, \mathrm{PM}_{10}(0.99 *) ; \mathrm{PM}_{2.5}, \mathrm{NO}_{2}(0.81 *) ; \mathrm{PM}_{10}, \mathrm{NO}_{2}(0.81 *) ; \mathrm{CO}, \mathrm{NO}_{2}$ $(0.77 *)$ and some negative correlations have also been found between $\mathrm{O}_{3}, \mathrm{NO}(-0.15) ; \mathrm{O}_{3}$ and $\mathrm{NH}_{3}(-0.36)$ in the pre-lockdown phase. The reduction amount of mean concentration from the pre-lockdown phase to during lockdown of the main pollutants like $\mathrm{PM}_{2.5}, \mathrm{PM}_{10}$ and $\mathrm{NO}_{2}$ are $\sim 58.71 \%, \sim 57.92 \%$ and $\sim 55.23 \%$. Near Rabindra Bharati University constant emission of $\mathrm{PM}_{2.5}, 10$ and $\mathrm{NO}_{2}$ have been recorded due to the nearby Cossipore thermal power station.
\end{abstract}

Keywords COVID-19 $\cdot$ India $\cdot$ Lockdown $\cdot$ Pollutants $\cdot$ Air quality $\cdot$ ANOVA

Mohan Sarkar

mohansrkrs@gmail.com

Anupam Das

anupamds908@gmail.com

1 Department of Geography, Visva-Bharati, Santiniketan, West Bengal 731235, India

2 Department of Geography, Panihati Mahavidyalaya, Sodepur, Kolkata, West Bengal 700110, India 


\section{Introduction}

In December 2019, a disease, later named COVID-19, was identified in Wuhan of China and within 3 months more than 100 countries have been affected by devastating consequences (Wang and Su 2020). On 11 March 2020, it was found that the spread of COVID19 is caused by the new Coronavirus SARS-CoV-2 and it was announced as a pandemic (Figueiredo et al. 2020). The first confirmed case of COVID-19 in India was identified on 30 January 2020 in Kerala and hiked to three by 3 February when three students returned from Wuhan, China, and the first death was recorded on 12 March. Till 3 May 2020, the cumulative number of total infection by COVID-19 was more than forty thousand across India (GOI 2020). West Bengal the fourth-most densely inhabited state in the country recorded the first positive case of COVID-19 on 17 March 2020 after a UK-returned student was tested positive. To avert the infection, countries have strictly restricted the movement of people and transportation, reducing human interactions, enforcing strict quarantine, prohibiting large-scale private and public gatherings, encouraging social-distancing, and restricting private and public transportations and economic behaviour (Fernandes 2020; He et al. 2020; Wang and Su 2020).

India has been following a nationwide lockdown since 24 March 2020, which was initiated with a voluntary public curfew on 22 March, followed by a 21-day lockdown starting from 24 March. Lockdown of the production sectors, restriction on human mobility, and controlled public transportation system have resulted in the lowering of emission of pollutants. Studies by various scholars have shown how the lockdown has improved the ambient air quality, like in India (Gautam 2020; Mahato et al. 2020; Sikarwar and Rani 2020; Srivastava et al. 2020), the USA (Berman and Ebisu 2020), Mexico (Méndez-Arriaga 2020), Kazakhstan (Kerimray et al. 2020), Iran (Abdul Halim et al. 2018), China (Fan et al. 2020; Zambrano-monserrate et al. 2020) especially in Wuhan (Cole et al. 2020; Lu et al. 2020; Sicard et al. 2020; Song et al. 2016; Wang and Su 2020), Barcelona in Spain (Tobías et al. 2020), Sao-Paulo in Brazil (Nakada and Urban 2020), Milan in Italy (Collivignarelli et al. 2020), and Salé City in Morocco (Otmani et al. 2020).

In India, air pollution has become a topic of intense debate at all levels mainly because of the enhanced anthropogenic activities, e.g. rapid urbanization, higher population growth, increased energy consumption, vehicular emission, and industrial emission (Dadhich et al. 2018; Ghose et al. 2005; Gupta et al. 2008). Kolkata is the most polluted metropolis in India and suffers from the highest pollution levels among eight tropical Asian countries; on the other hand, Howrah is considered as one of the highly industrialized districts in the West Bengal (Mukherjee et al. 1998; Upadhyay et al. 2014; Financial Express 2020). The contribution of urban areas in the nation's GDP is gradually increasing in India (Ghose et al. 2005). Hence, the pollution due to vehicular emission (Chowdhury 2015), thermal power plant (Ghose et al. 2004), small-scale industries, industrial clusters, residential areas (Gupta et al. 2008), and street shops (NGT) are increasing in Kolkata and Howrah. Kolkata shares minimum areas for road connectivity only 6\%, lesser than Mumbai and Delhi, and the encroachment of roads, on-road illegal parking adds fuel to this problem (Chakrabartty and Gupta 2014). Improving economic conditions and more women's participation in outside jobs has increased the demand for private cars (Chakrabartty and Gupta 2014). The hiking demand for private transportation and other vehicles in Kolkata city without proper traffic management is responsible for the day-by-day increasing pollution (Bhattacharjee 2008). In Kolkata vehicular emission, industrial centres and domestic sources contribute $50 \%, 48 \%$, and $2 \%$ of the total pollution and heavy industries shares 56 percent and 44 
percent is shared by the small-scale industries of the total industrial emission (Government of West Bengal 2019). This study aims to evaluate the changes in air quality in terms of pollutant concentration during the implementation of the lockdown measures considering the COVID-19 pandemic in Kolkata and Howrah, the 'twin cities' of West Bengal.

\section{Materials and methods}

\subsection{Study area}

Kolkata at the eastern bank and Howrah at the western bank of Hooghly River are 'the twin city' of West Bengal (Fig. 1). The 'city of joy' Kolkata was also the capital of India during the British empire and Howrah is the adjacent main city (Debnath et al. 2018; Haque and Singh 2017). According to the 2001 census, Kolkata is the second most populous city in India with a population of 14.4 million, after Mumbai while the population of Howrah is 10 million. Kolkata and Howrah rank 9th and 30th in world population ranking with a population density of 24,252 persons $/ \mathrm{km}^{2}$ and 20,817 persons $/ \mathrm{km}^{2}$, respectively (Census of India 2011). The population of Kolkata and Howrah is ever increasing due to population growth and labour influx (Debnath et al. 2018).

The pollution level of Kolkata is close to Delhi and higher than that of Mumbai and Chennai in India (Roy et al. 2015). It has also been known as 'the dusty city' (Haque and Singh 2017). In 2018, World Health Organization (WHO) confirmed that Kolkata is the second most polluted metropolis in the country, next only to Delhi. The study revealed another alarming trend that Kolkata's air quality is declining faster than that of Delhi. Kolkata and Howrah industrial belt are considered to be one of the highly industrialized

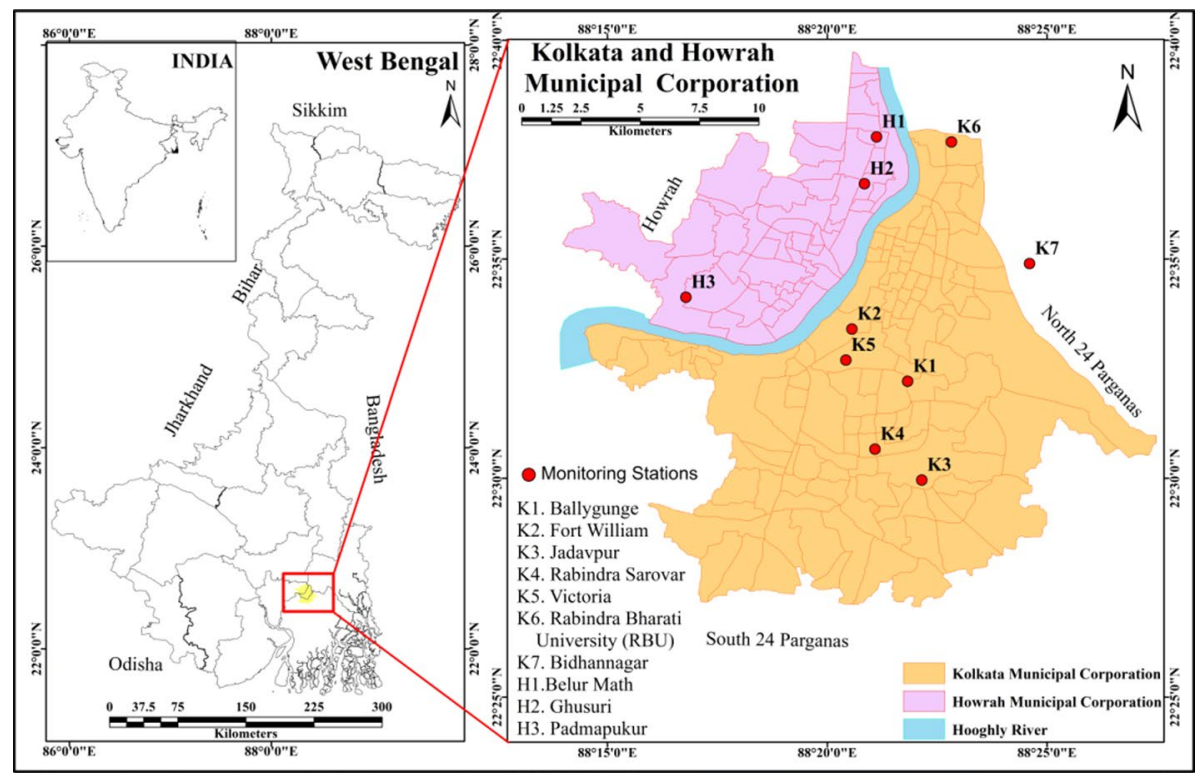

Fig. 1 Location of the study area 
districts in West Bengal where industries like engineering, casting, steel fabrication, shipbuilding, consumer goods industries, construction pressure die casting, forging, electric installations, manufacturing of industrial electrical goods accessories, etc. are highly concentrated (Upadhyay et al. 2014). Vehicular emissions from continuously increasing vehicles contribute a large in polluting air, and the number has increased 8 times from 1951 to 2001 (Chowdhury 2015). After the implementation of various measures still, vehicular emission is very high and threatening at traffic intersections in Kolkata (Ghose et al. 2004, 2005). $\mathrm{PM}_{2.5}$ and $\mathrm{PM}_{10}$ are considered to be the main pollutants and have a constant concentration above the permissible level in Kolkata (Das et al. 2015). The northern part of Kolkata is mainly characterized by the residential areas, small-scale industries, and Cossipore thermal power station and is surrounded by Hooghly River. The location of Dhapa dumping ground and east Kolkata wetland impacts the ambient air quality in the eastern part as well as the small-scale industries, and high traffic junctions in the central Kolkata pollute the air (Gupta et al. 2008). Due to densely distributed small-scale industries without any pollution controlling measures, unplanned traffic flow, and congestion, Howrah city is to endure higher pollution of ambient air (Upadhyay et al. 2014).

Urban morphology differs from north Kolkata to south. North Kolkata is condensed with old buildings and the roads which are very narrow and traffic congestion is another problem but high-rise buildings, highways with more space, and traffic congestion can only be noticed during office hours in the southern Kolkata (Mondal et al. 2000). Small-scale industries (Datta et al. 2016), burning ghats, thermal power stations (Chowdhury 2015) contribute a lot to the level of pollution in both Kolkata and Howrah municipal corporation. Major clusters of polluting sites in Kolkata are Pyrabagan, Maniktala (Battery Patti), Topsia, Picnic Garden, Tangra-Tijalia-Topsia (Charma Patti), Tangra-Kill Khana-Pangladanga, Hazra-Ritchie Road, Raja Bazar, Khiddapore-Garden Reach-Metiabruz, Cossipore-Chitpur, Bowbazar, Mullick Bazar, Jadubabur Bazar, Maniktala-PhoolBagan, Taratola Industrial Estate, Dhapa Landfills, MollarBheri, etc. (Datta et al. 2016). Based on health effects and level of pollution, Central Pollution Control Board categorized the industrial activities in red, orange, green, and white aiming to control the level of pollution and understand the pattern of industries under section 18(1) (b) of water (Prevention and control of pollution) (West Bengal Pollution Control Board 1981). Air quality is monitored automatically at six points in Kolkata Municipal Corporation, one at Bidhannagar and three locations in Howrah Municipal Corporation.

Ballygunge Ballygunge is situated at the central part of $\mathrm{KMC}$, and this area is known for condensed small-scale industries. It has recorded a high pollution level due to major road intersections near like Park Circus Seven Point Crossing, Gariahat, Rashbehari, and Hazara More (Chowdhury 2015). Tannery processing industries of Park circus and Kustia are adjoined to the station as an important industrial cluster.

Fort William and Victoria This part is situated in the western part of Kolkata near Hooghly River, and the main source of pollution is vehicular emission. The major roads those have connected this area with the other part of Kolkata are Khidirpur Road, Acharya Jagadish Chandra Bose Road, and Jawaharlal Nehru Road also Esplanade is another important traffic intersection.

Jadavpur Jadavpur where vehicular emission is very important is another automated station which is located in the southern part of the study area. Jadavpur is highly connected by roads and highly congested, and the major traffic intersections are the intersection of King Anwar Shah and Gariahat road and the flyovers near the K8 bus stand. The queue of the vehicles is seen from South City Mall to Jadavpur PS in the morning from 8.00 am to $11 \mathrm{am}$ and in the afternoon as well as night from 7.30 to 8.30 and $9.00 \mathrm{pm}$ (Nandi 2017). 
Rabindra Sarovar Rabindra Sarovar Station is located at the central Kolkata and is affected by high vehicular emission due to the high traffic intersections and roads like Tallygaunge Phari (Chowdhury 2015). Goal Park is the intersection of Gariahat Road and Dr. MeghnathSaha Road, the intersection of Debika Kumar road and Baroj Road, Rashbihari, and Hazra intersection are major traffic intersection.

Rabindra Bharati University $(R B U)$ This station is the northernmost among the other stations in KMC. An important entry point in Kolkata is Vivekananda Setu, and the road is always congested with loaded trucks (Ghose et al. 2005) and also it is influenced by the nearby Cossipore thermal power station, high traffic congestion, electro-plating industry, and dyeing industry (Karar et al. 2006), Gold smelting stations (red category industry), and burning ghats are important sources of pollution near RBU (Ghose et al. 2005).

Bidhannagar Bidhannagar is one of the busiest areas. The location of the administrative centres of West Bengal near Salt Lake is connected through Biddhannagar Road Railway Station which is a reason for higher traffic as well as human mobility in this part. Uncontrolled traffic movement, a higher number of auto-rickshaw, bus, and taxi are very important for traffic congestion.

In Howrah Municipal Corporation, only three automated stations among which Belur Math is located in the northern part of HMC, Ghusuri near Liluah Station, and Padmapukur at the southern part of HMC are set to record pollutants' data. Howrah is an industrial centre in West Bengal, and unplanned growth of the city and squatter settlement are responsible for relatively higher pollution in Howrah, West Bengal.

Belur Math The station is located at the northernmost part of HMC and affected by the nearby manufacturing industries like aluminium production, plastic production, chemical industries, and electronics. Within $200 \mathrm{~m}$ of radius, the Belur Bazar traffic intersection and Belur Bus terminus are the important traffic intersection and the two main roads that have crossed from the eastern and the western part of the station are Al Banerjee Road and Girish Ghosh Road and another important road is Ramlochan Street.

Ghusuri Ghusuri has its name in history as an industrial centre in West Bengal. This part is now famous for plastic and aluminium industries which are categorized as the 'red' by WBPCB, 2018. Highly condensed settlement patterns are mainly characterized by squatter settlement.

Padmapukur Padmapukur is the southernmost station in HMC. The level of pollution is relatively higher in this part, an intersection of Andul Road, NH 117, Botanical Garden road.

\subsection{Data sources}

To study the changes in air quality during the lockdown period, the data from ten monitoring sites in Kolkata Municipal Corporation (KMC), as well as in Howrah Municipal Corporation (HMC) (Table 1), are taken into consideration. Monitoring station Bidhannagar is considered for spatial mapping purposes only for better understanding and excluded from all the statistical analysis because the eastern part is only covered by this station but does not come under KMC. The location of all these ten monitoring stations is shown in Fig. 1. Data from 22 February 2020 to 23 March 2020 (4 weeks before the lockdown) and from 24 March 2020 to 3 May 2020 (tenure of complete lockdown) were used to calculate variations in concentrations and appraise the relative change from the pre-lockdown period to the complete lockdown period. 
Table 1 Location of the monitoring stations

\begin{tabular}{llll}
\hline Municipal corporation & Station ID & Name of the station & Location \\
\hline Kolkata & K1 & Ballygunge & $22^{\circ} 32^{\prime} 12.3^{\prime \prime}, 88^{\circ} 21^{\prime} 49.69^{\prime \prime}$ \\
& K2 & Fort William & $22^{\circ} 33^{\prime} 23.9^{\prime \prime}, 88^{\circ} 20^{\prime} 33.63^{\prime \prime}$ \\
& K3 & Jadavpur & $22^{\circ} 29^{\prime} 57.44^{\prime \prime}, 88^{\circ} 22^{\prime} 9.01^{\prime \prime}$ \\
& K4 & Rabindra Sarovar & $22^{\circ} 30^{\prime} 39.82^{\prime \prime}, 88^{\circ} 21^{\prime} 5.11^{\prime \prime}$ \\
& K5 & Victoria & $22^{\circ} 32^{\prime} 41.31^{\prime \prime}, 88^{\circ} 20^{\prime} 25.33^{\prime \prime}$ \\
& K6 & Rabindra Bharati Univer- & $22^{\circ} 37^{\prime} 40.35^{\prime \prime}, 88^{\circ} 22^{\prime} 49.44^{\prime \prime}$ \\
& K7 & sity (RBU) & \\
Bidhannagar & Bidhannagar & $22^{\circ} 34^{\prime} 53.65^{\prime \prime}, 88^{\circ} 24^{\prime} 36.09^{\prime \prime}$ \\
Howrah & H1 & Belur Math & $22^{\circ} 37^{\prime} 47.28^{\prime \prime}, 88^{\circ} 21^{\prime} 7.26^{\prime \prime}$ \\
& H2 & Ghusuri & $22^{\circ} 36^{\prime} 43.08^{\prime \prime}, 88^{\circ} 20^{\prime} 50.72^{\prime \prime}$ \\
& H3 & Padmapukur & $22^{\circ} 34^{\prime} 7.43^{\prime \prime}, 88^{\circ} 16^{\prime} 47.02^{\prime \prime}$ \\
\hline
\end{tabular}

The West Bengal Pollution Control Board (WBPCB), under the guidance of the National Air Quality Monitoring Program (NAMP), regularly monitors the ambient air quality of major urban towns and industrial areas of the state. The daily concentration of seven pollutants including particulate matter $\left(\mathrm{PM}_{2.5}\right.$ and $\left.\mathrm{PM}_{10}\right)$, nitrogen dioxides $\left(\mathrm{NO}_{2}\right)$, sulphur dioxide $\left(\mathrm{SO}_{2}\right)$, ammonia $\left(\mathrm{NH}_{3}\right)$ on $24 \mathrm{~h}$ interval on the other hand ozone $\left(\mathrm{O}_{3}\right)$, and carbon monoxide (CO) have been taken into consideration on an 8-h interval for air quality assessment from the Central Pollution Control Board online portal for air quality data dissemination (https://app.cpcbccr.com/ccr/\#/caaqm-dashboard-all/caaqm-landing) to give an inclusive analysis of the air quality data under the national ambient air quality standards. In the AQI system $\mathrm{PM}_{2.5}, \mathrm{PM}_{10}, \mathrm{NO}_{2}, \mathrm{SO}_{2}, \mathrm{NH}_{3}, \mathrm{CO}, \mathrm{O}_{3}$, and $\mathrm{Pb}$ but here $\mathrm{Pb}$ is excluded because the concentration of this pollutant is not available in real time and cannot be taken into consideration for real-time AQI calculation (CPCB 2014). These data are also verified from different sources like AQI-India (https://app.cpcbccr.com/AQI_India/) under the Central Pollution Control Board, WBPCB (https://emis.wbpcb.gov.in/airquality/JSP/aq/distr ictwiseReport.jsp) under West Bengal Pollution Control Board and OpenAqportal (https ://openaq.org/\#/location/Arya\%20Nagar,\%20Bahadurgarh\%20-\%20HSPCB?_k=cpmf34).

Concentrations of $\mathrm{NO}_{2}\left(0.25^{\circ}\right.$ level-3 (L3) daily OMI tropospheric) for the period of 22 February to 3 May of 2019 and 2020 were acquired from Giovanni interface (https://giova nni.gsfc.nasa.gov/giovanni/), derived from the NASA Goddard EarthSciences Data Active Archive Center (GES DISC; https://disc.sci.gsfc.nasa.gov).

\subsection{Data analysis}

The air quality index (AQI) is a measure of the cumulative effect of individual pollutants concentration on the quality of air in different places, but the modification of the method which is termed as National Air Quality Index (NAQI) is based on the maximum operator approach to avoid the uncertainty (CPCB 2014; Dadhich et al. 2018; Joshi and Mahadev 2011; Mahato et al. 2020). Central pollution control board (CPCB), India, monitors the ambient air continuously and has been using the EPA-US method to calculate the air quality indices (AQI) (Chaurasia et al. 2013; Kumar and Dash 2018). Here we only briefly summarized it. Calculation of Sub-indices for each and individual pollutant and then the aggregation of breakpoint values (sub-indices), which depend upon the Indian National 
Ambient Air Quality Standards (NAAQS), are the two steps involved in AQI calculation. The maximum value of the sub-indices is taken as the AQI. The AQI standards are displayed in the number form that describes the quality rating (potential health effects) as shown in Table 2.

As the study is carried out in KMC and HMC, the municipal ward boundary map is designed in a GIS environment. ArcGIS 10.3, distributed by the Environmental Systems Research Institute (ESRI), has been employed for spatial analysis to identify air pollution levels. Based on the ten monitoring sites, the interpolated maps of each pollutant and AQI have been generated from pre-lockdown tenure to during lockdown tenure. In this study, inverse distance weighting (IDW) interpolator by linear combination model has been used because it is easy to operate than others without any pre-program assumptions to opt for a semi-variogram model (Jumaah et al. 2019; Poshtmasari et al. 2012).

ANOVA (Two-way), cluster analysis (single linkage) based on the Euclidean distance and Ward's methods, and Pearson moment correlation coefficient $(r)$ were computed using the IBM SPSS version23. STATA 12 was used for the Box plots of AQI. The ANOVA helps to understand the variation in air quality index in each location as well as in prelockdown and during lockdown tenure, while correlation analysis denotes the degree of association among the different pollutants is done using JMP 15. Box plots are especially valid for comparing two or more distribution and also present a graphical display based on the order-statistic summaries of median and quartiles. Tables and charts have been used to report descriptive statistics by calculating the simple percentage, tabulation, and crosstabulation. Using MS Excel line graphs for each pollutant is graphically represented.

\section{Results and discussion}

\subsection{Observed concentration of the air pollutants}

The concentration of the pollutants in the study area is summarized (Table 3) to understand the changes in maximum-minimum concentration and mean concentration of the pollutants, for all the concerned recording stations of the 'twin city' for the pre-lockdown (PL) period from 22 February to 21 March and the during lockdown (DL) period from 24 March to 3 May 2020. The effect of $\mathrm{PM}_{2.5}$ and $\mathrm{PM}_{10}$ is severe on the health of people as it results in severe breathing problems as well as lung problems (Ashhar et al. 2007). Particulate matter is the most important pollutant in Kolkata, caused almost 10,000 premature deaths in Kolkata in 1995 (Kazimuddin and Banerjee 2015). For all the stations, a sharp reduction has been noted in the concentration of $\mathrm{PM}_{2.5}$ and $\mathrm{PM}_{10}$ from the prelockdown to during lockdown. The highest concentration with an amount of $149.68 \mu \mathrm{g} / \mathrm{m}^{3}$ has been monitored at Ballygunge because the station is nearest to the Garden reach and other small-scale industrial centres in the area for $\mathrm{PM}_{2.5}$ in Kolkata, whereas Gusuri is one of the most industrial centres in Howrah and has recorded an amount of $333.52 \mu \mathrm{g} / \mathrm{m}^{3}$ for $\mathrm{PM}_{10}$ in Howrah at $24 \mathrm{~h}$ interval as well. In the pre-lockdown tenure, the monitored amount of $\mathrm{PM}_{2.5}$ is above the level of the AQI standards because of intensive industrial belts such as paper pulp, chemical industries, textile, rubber, and iron as well as high traffic congestion and emission from the thermal power plants which are associated with the corresponding stations (Spiroska et al. 2013). The reduction of 2.75 times of $\mathrm{PM}_{10}$ at Ghusuri along with the mean difference between the pre-lockdown and during lockdown is $125.4 \mu \mathrm{g} / \mathrm{m}^{3}$. On the other hand, minimum concentration has been recorded at Belur Math with a mean 







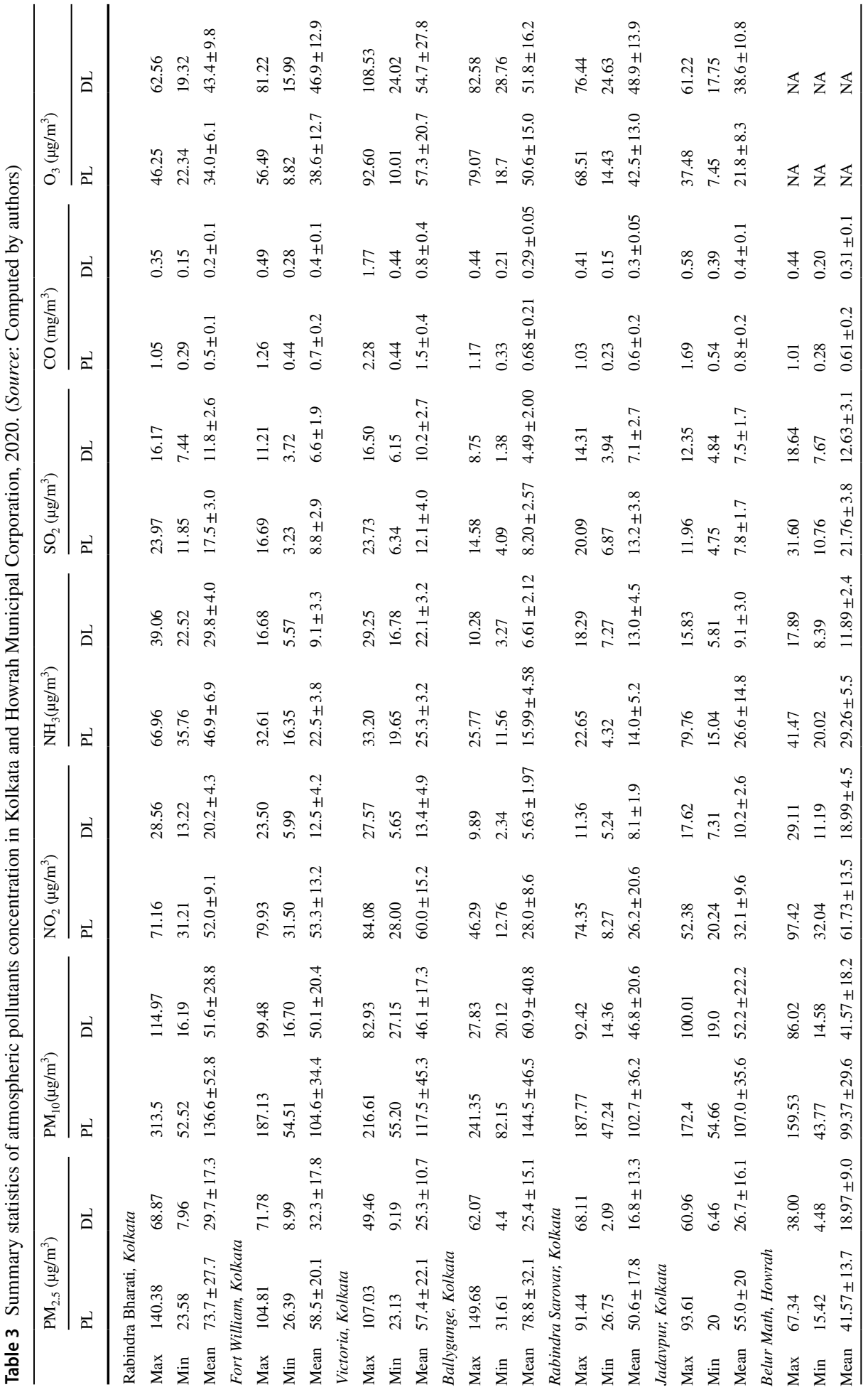







concentration of $41.57\left(\mu \mathrm{g} / \mathrm{m}^{3}\right)$ after the imposition of lockdown. The complete lockdown has reduced the power consumption, traffic congestion, and emission from the production units to a very minimal level. The 'Red' category industries like chemical industries, plastic industries, electronic industries, etc. and jute, paper pulp industries are responsible for high emission.

Severe degradation of air quality is also caused by $\mathrm{NO}_{2}$ and affects health severely such as breathing problems, headache, and corrosion of teeth (Ashhar et al. 2007). It is emitted from both the natural sources of the nitrogen cycle by the process of biological processes, lighting effect, and the anthropogenic sources as vehicular emission from the highly congested traffic flow (Ibe et al. 2020). During weekends, average traffic flow is $2.3 \times 10^{4}$ and it is raised to $2.8 \times 10^{4}$ during weekdays near industrial centres in Kolkata (Gupta et al. 2008). From studies, it has been found that the $\mathrm{NO}_{2}$ concentration is double than of the CPCB standard of 60 in the residential areas (Bhattacharjee 2008). The highest concentration of $\mathrm{NO}_{2}$ has been recorded at Belur Math in $\mathrm{HMC}$ and a reduction of 3.24 times during lockdown from the pre-lockdown phase. The minimum value is recorded during the lockdown period at Padmapukur, HMC. During the complete lockdown period, Belur Math has recorded the highest concentration and followed by Victoria, Fort William, Ghusuri, Rabindra Bharati, Padmapukur, Jadavpur, Ballygunge, and Rabindra Sarovar. $\mathrm{SO}_{2}$ with a higher amount may cause death only if anyone is already suffering from previous respiratory problems like emphysema and the effect is more on the older people than young people (Ashhar et al. 2007).

$\mathrm{SO}_{2}$ as an atmospheric gas is released when coal is burnt, decaying of grassland or vegetation, volcanoes, and ocean. It is a precursor of acid rain in the form of sulphuric acid $\left(\mathrm{H}_{2} \mathrm{SO}_{4}\right)$, deposits in the surface and sub-surface, and also in oxidized form as sulphate having a dominating role in 'radiative forcing' of climate (Cox 2003; Wang et al. 2006). From the study, it has been found that $60 \%, 36 \%$, and $7.8 \%$ are released from transport, industrial, transport, and other activities share very little in India (Garg et al. 2001). The concentration of SO2 tends to be higher during the high traffic hours in urban areas (Gaur et al. 2014). A four-time reduction in mean concentration is noted from pre-lockdown to during the lockdown period at Ghusuri in HMC.

Ozone is produced and directly emitted because of reactions among nitrogen oxide (primary pollutant), certain organic compounds, and precursor of methane $\left(\mathrm{CH}_{4}\right)$ mixed in the air under the influence of ultraviolet rays (Arbilla et al. 2002). The lifespan of ozone varies from an hour to a day in the normal situation but in the polluted urban atmosphere, it may vary from day to week. Temperature affects the formation of ozone and also the magnitudes of concentration in the atmosphere because the decreasing temperature results in the decomposition of the precursors as well as the high solar radiation amplifies the production of ozone in the atmosphere (Pulikesi et al. 2006). Due to the unavailability of the data at Belur Math, the station is not considered for discussion. Victoria and its adjoining areas are prominent for the concentration of $\mathrm{O}_{3}$, which varies from 10.1 to $92.60 \mu \mathrm{g} / \mathrm{m}^{3}$ in the pre-lockdown period but the concentration has hiked to $24.02-108.53 \mu \mathrm{g} / \mathrm{m}^{3}$ in the during lockdown period.

$\mathrm{NO}$, as a harmless gas is directly emitted from the vehicle (85-87.5) and then transformed into $\mathrm{NO}_{2}$ in reaction with the $\mathrm{O}_{3}$ and the other nitrogen compounds by other chemical processes, the combination of $\mathrm{NO}_{2}$ and $\mathrm{NO}$ is known as NOx (Palmgren et al. 1996). The ratio between NO and NOx is very important and known as the 'Leighton ratio' in the atmosphere and controls the magnitude of $\mathrm{O}_{3}$ (Leighton 1962).

Ozone concentration has been hiked because ozone can be degraded and regenerated by $\mathrm{NO}_{\mathrm{x}}$ and more degradation is associated with urban areas where local scale 
ozone depletion is found near high $\mathrm{NO}_{\mathrm{x}}$ emitting zone (Arbilla et al. 2002). During the lockdown period, the emission of $\mathrm{NO}_{2}$ is reduced and has limited the degeneration process of ozone, results in continuous hiking of ozone in the atmosphere.

$\mathrm{CO}$ is a trace gas, emitted due to incomplete combustion of fossil fuel and reaction among oxidation of hydrocarbons, volatile organic compounds, and methane, also from the vehicle, industrial hubs, open burning as well as aircraft emission (Jaffe 2012) and wood fires (Aneja et al. 2001; Gaur et al. 2014; Njoku et al. 2016). The diurnal pattern varies highly based on human activities in urban centres (Jaffe 2012). National Green Tribunal (2019) reported that street food stalls on footpaths use charcoal, dump cake, and other materials as fuel are the sources of severe pollution in Kolkata. Victoria has recorded the highest concentration of $\mathrm{CO}$ that ranges from 0.44 to $2.28 \mathrm{mg} / \mathrm{m}^{3}$ in the pre-lockdown phase and is reduced to $0.44-1.77 \mathrm{mg} / \mathrm{m}^{3}$. During the pre-lockdown phase, the highest concentration is found in Victoria because the vehicle is very important source of $\mathrm{CO}$, and the traffic intersections near Victoria contribute a lot to the atmosphere. Hence, the minimum concentrated zone of $\mathrm{CO}$ is Rabindra Bharati.

$\mathrm{NH}_{3}$ is an alkynes gas, emitted from both the anthropogenic processes (animal waste, fertilizer, waste management, vehicular emission, incomplete burning of homecooking fuel, and dumping stations) and atmospheric processes (Fenn et al. 2018). In Kolkata, a high concentration of $\mathrm{NH}_{3}$ can be traced out where the land use pattern is dominated by industrial, commercial, and residential areas associated with dumping stations (Gupta et al. 2008). During the pre-lockdown phase, $\mathrm{NH}_{3}$ has taken the highest concentration at Jadavpur. The engrossment ranges from 15.07-79.76 to 5.81-15.04 $\mu \mathrm{g} / \mathrm{m}^{3}$ the during lockdown phase. The mean concentration has dropped from 26.6 to $9.1 \mu \mathrm{g} / \mathrm{m}^{3}$, almost a three times reduction from the pre-lockdown to during lockdown.

Line graphs (Fig. 2) have been drawn based on pollutant concentration data for all the stations in KMC and HMC are averaged and then plotted. It represents the trend of the concentration of the pollutants. $\mathrm{NO}_{2}, \mathrm{SO}_{2}, \mathrm{CO}, \mathrm{O}_{3}, \mathrm{NH}_{3}$ have been recorded at a satisfactory level but it has been noted that $\mathrm{PM}_{2.5}$ and $\mathrm{PM}_{10}$ are above the satisfactory level in the pre-lockdown phase and can be considered as the main pollutants in both KMC and HMC. But during the lockdown phase, the concentration has been reduced to a satisfactory level for all the pollutants except $\mathrm{O}_{3}$. The main scaling down can be noted for $\mathrm{PM}_{2.5}$ and $\mathrm{PM}_{10}$ from the pre-lockdown to the complete lockdown period. AQI is the combined form of all the pollutants is also showing that during the lockdown period the air quality has improved to the 'good' category.

The box plots (Fig. 3) of all stations are depicting the change in AQI from pre-lockdown to during lockdown. In pre-lockdown tenure, the station Ballygunge in Kolkata Municipal Corporation has been noted for 'poor' air quality as prescribed by CPCB (2014) (Table 2) because of the nearby polluting sites like Topsia, Kosba, and Mullickbazar industrial sites (Gupta et al. 2008).

Most of the stations have recorded 'good' to 'satisfactory' air quality during the lockdown period in both the municipal corporations. Among all the stations Ballygunge has recorded highest AQI during the pre-lockdown phase and the median value is 163.67 but during lockdown phase the median of AQI has reduced to 58.29. From the diagram (Fig. 3), the major polluted stations are Ballygunge, Rabindra Bharati University, and Ghususri. The lowest AQI has been recorded during the lockdown period at Belur Math in Howrah Municipal Corporation. 



$\mathrm{KMC}$

$\mathrm{HMC}$

Fig. 2 24-h mean concentrations of $\mathbf{a} \mathrm{PM}_{2.5}$, b $\mathrm{PM}_{10}, \mathbf{c ~ N O} \mathrm{NO}_{2}$, d $\mathrm{NH}_{3}, \mathbf{e ~} \mathrm{SO}_{2}$, h AQI and 8-h mean concentrations of e $\mathrm{CO}$ and $\mathbf{f} \mathrm{O}_{3}$ between 22 February and 3 May 2020 in Kolkata and Howrah

\subsection{Cluster analysis}

Cluster analysis is a multivariate analysis that has been used to determine the grouping pattern of the monitoring stations in the pre-lockdown and during the lockdown phase based on AQI (Fig. 4). Euclidean distance and Ward's methods were employed to measure the distance among stations (David et al. 2019).

In the pre-lockdown phase, the stations Jadavpur, Rabindra Sarovar, Fort William, and Victoria located in the central part of the study area are in the first cluster notifying the 


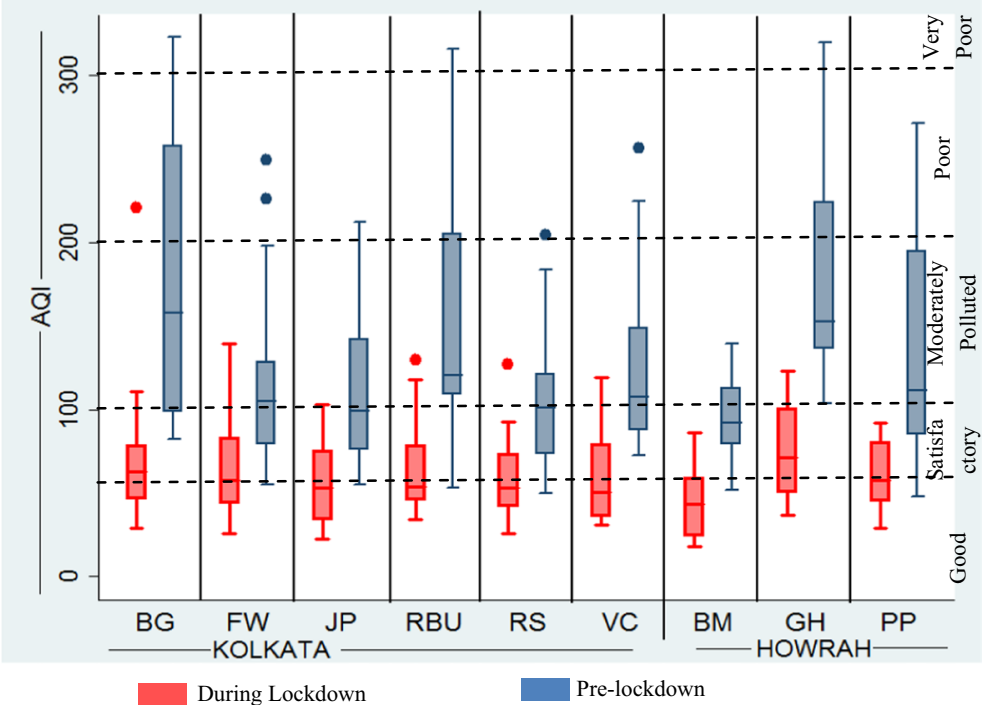

Fig. 3 Box plot comparing AQI distribution for nine monitoring stations between pre-lockdown and during lockdown phase ( $B G$ Ballygunge, $F W$ Fort William, $J P$ Jadavpur, $R B U$ RabindraBhararti University, $R S$ Rabindra Sarovar, $V C$ Victoria, $B M$ Melur Math, $G H$ Ghusuri, PP Padmapukur)



Fig. 4 Cluster analysis of the stations in the a pre-lockdown and $\mathbf{b}$ during lockdown period ( $B G$ Ballygunge, $F W$ Fort William, $J P$ Jadavpur, $R B U$ RabindraBhararti University, $R S$ Rabindra Sarovar, $V C$ Victoria, $B M$ Melur Math, $G H$ Ghusuri, $P P$ Padmapukur)

same level of pollution (Fig. 4a). The AQI is similar for these stations RBU, Ghusuri, Ballygunge, and Padmapukur and has made a cluster because Ghusuri and RBU are affected by the nearby Cossipore thermal power station whereas Ballygunge is located among the local small-scale industries in KMC, and Padmapukur is also affected by pollution from smallscale industries in HMC. During the lockdown period, the clustering patterns (Fig. 4b) have changed. Fort William, Rabindra Bharati University, Victoria, and Ghusuri have made a cluster, and the rest of the stations have made the other clusters. 


\subsection{Spatial distribution of pollutants}

The cluster analysis has shown the pattern of clusters of the stations based on the AQI. Spatial variability has been represented in the form of a spatio-temporal map for the pollutants and the AQI from the pre-lockdown phase to during the lockdown phase for few selected days. The variability is represented based on the pollutants for each of the stations. Different factors like vehicular emission are a most important factor for Kolkata and the decennial growth of vehicle is like two wheelers almost $70 \%$ followed by four wheelers (20\%), three wheeler (10-14\%), and bus (8-13\%) and the high traffic flow junctions are Park Circus even point junction, B.B.D Bag, Gariahat, Rashbehari, Ballygunge, M.G Road (Chowdhury 2015). Kolkata-Howrah industrial belt is another important source of pollution. Howrah is known for its intense small-scale industries (Upadhyay et al. 2014). The main sites of industrial pollution are Pyarabagan, Garden Reach, Taratala, Mallickbazar, Dhapa, and Cossipore thermal power station (Datta et al. 2016).

$\mathrm{PM}_{2.5}, \mathrm{PM}_{10}$ and $\mathrm{NO}_{2}$ are the major pollutants in Kolkata and its adjoining areas (Datta et al. 2016). To avoid the climatic variables in the present study, the maps are used to show how the difference in level of pollution between two consecutive years. In 2019 due to the activity of industries, thermal power stations, vehicular and street shops, etc. the concentration of both $\mathrm{PM}_{2.5}$ and $\mathrm{PM}_{10}$ which are shown in red colour on the map was very high as in Fig. 5a while in 2020 on the same period the concentration of particulate matters in the atmosphere is considerably much lesser than the previous year (Fig. 5b), due to restricted emission from vehicles, construction sites, and factories during complete lockdown tenure.

24-hour timely averaged map of $\mathrm{NO}_{2}\left(1 / \mathrm{cm}^{2}\right)$ from 24 March to 3 May 2019 (Fig. 6a) from the NASA Giovanni and concentration from 24 March to 3 May 2020 (Fig. 6b), the tenure of the complete of lockdown in India is compared. Here a significant reduction has been seen in the $\mathrm{NO}_{2}$ concentration over Kolkata and Howrah as well as West Bengal as compared to the same phase of the previous year.

To show the spatial variability of pollutants in the pre-lockdown and during the lockdown phase in particularly Kolkata and Howrah Municipal Corporation, 1 March and 13 March during the pre-lockdown span, 24 March, the day when lockdown started, 7 April and 3 May during lockdown, are chosen. The day of Janta Curfew played an important role in bringing down the pollution level in Kolkata and Howrah Municipal Corporation.

$\mathrm{PM}_{2.5}$ (Fig. 7) and $\mathrm{PM}_{10}$ (Fig. 8) are the two most important pollutants in Kolkata and Howrah (Das et al. 2015). A high concentration of $\mathrm{PM}_{2.5}$ is recorded especially near Ghusuri, Howrah (Fig. 7). Another two most important concentration zones can be found near

a





Fig. 5 Change in concentration from 1 April 2019 to 2020 of $\mathrm{PM}_{2.5}$ (a) and $\mathrm{PM}_{10}$ (b). (Source: https://earth .nullschool.net) 


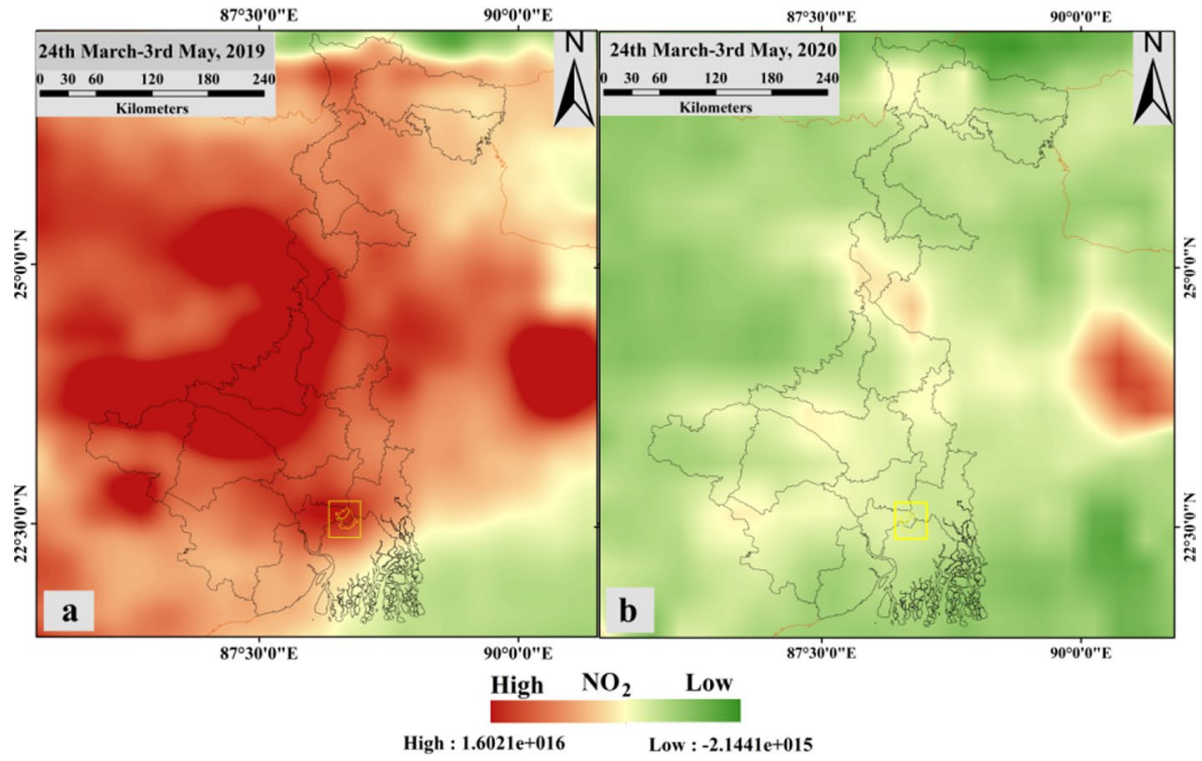

Fig. 6 24-h timely averaged map of $\mathrm{NO}_{2}\left(1 / \mathrm{cm}^{2}\right)$ from a 24 March to 3 May 2019, b 24 March to 3 May 2020. (Source: NASA Giovanni)


Fig. 7 Spatio-temporal change of $\mathrm{PM}_{2.5}$ (2020)

RBU due to its stone-throwing distance to Cossipore power station as the main source of $\mathrm{PM}_{2.5}$ and $\mathrm{PM}_{10}$ and another is near Ballygunge as this part is surrounded by nearby industrial centres like Mullick Bazar, Picnic Garden, Topsia and Kasba (Das et al. 2015). On 13 March, the reduction in concentration can be noticed only at Ghusuri. On 24 March, the concentration has flattened due to the Janta Curfew on 22 March, shutting down of the industries, reduction in traffic flow, shutting down of street cooking shops, and reduction in power consumption (The Economics Times 2020). On 7 April, a slight increase can be 



Fig. 8 Spatio-temporal change of $\mathrm{PM}_{10}(2020)$

noted and then again a fall in concentration is reported. Ghusuri recorded medium concentration also during the lockdown period. So this part has a constant emission of $\mathrm{PM}_{2.5}$. The pattern of concentration of $\mathrm{PM}_{10}$ is the same as $\mathrm{PM}_{2.5}$, it may be because of almost the same sources of emission (Ibe et al. 2020).

Major $\mathrm{NO}_{2}$ emitting zones (Fig. 9) are found at Belur Math $\left(97.42 \mu \mathrm{g} / \mathrm{m}^{3}\right)$, Rabindra Bharati $\left(59.33 \mu \mathrm{g} / \mathrm{m}^{3}\right)$, in the northern part and Fort William $\left(73.25 \mu \mathrm{g} / \mathrm{m}^{3}\right)$ and Victoria $\left(79.36 \mu \mathrm{g} / \mathrm{m}^{3}\right)$ in the central part on 1 March. The location of Belur Math station in the 'Belur Induatrial Belt' and the association of manufacturing industries are responsible for high $\mathrm{NO}_{2}$ emission as well as the Belur bus terminus and the Belur Bazar traffic intersection are very important for vehicular emission. Rabindra Bharati University is influenced by Cossipore thermal power station, burning ghats, and important traffic intersections (Karar et al. 2006). Victoria has recorded higher $\mathrm{NO}_{2}$ concentrations because of the nearby
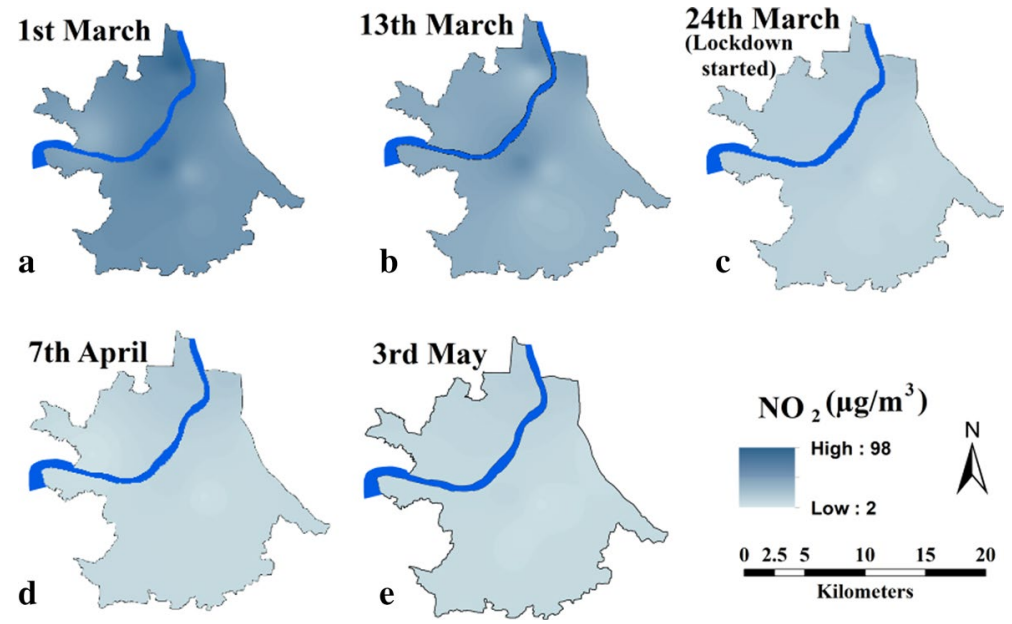

Fig. 9 Spatio-temporal change of $\mathrm{NO}_{2}(2020)$ 
traffic intersections like Khidirpur Road, Acharya Jagadish Chandra Bose Road, Jawaharlal Nehru Road, and Esplanade. Zones of medium concentration are found in the extreme western Kolkata, limited areas of central Kolkata, and the eastern part of Kolkata due to high traffic flow (Gupta et al. 2008). From 13 march before lockdown a slight reduction can be seen (Fig. 9) due to less traffic flow in Kolkata, a moderate concentration is reported. On the day of 24 March when the most important stations like Blur Math and Victoria have recorded very minimum concentration of $\mathrm{NO}_{2}$ with an amount of $22.85 \mu \mathrm{g} / \mathrm{m}^{3}$ and $19.01 \mu \mathrm{g} / \mathrm{m}^{3}$, respectively, the concentration was scaled down due to Janta Curfew on 22 March that can be a probable factor, and after 24 March concentration pattern is almost the same for all the stations.

The major concentration of $\mathrm{NH}_{3}$ (Fig. 10) is identified near RBU $\left(54.01 \mu \mathrm{g} / \mathrm{m}^{3}\right)$ and Belur Math $\left(41.47 \mu \mathrm{g} / \mathrm{m}^{3}\right)$ on 1 March. The $\mathrm{NH}_{3}$ concentration at Kosba is high because of animal wastes, livestock, and fertilizer (Carmichael et al. 2003) as a result the concentration at this station is highest during the pre-lockdown period. The concentration has reduced at this part to 8.83 on 3 May, and on the other hand, Rabindra Bharati University (22.52) has recorded a relatively higher amount on that particular day. Dhapa solid waste dumping station in the east margin of Kolkata is responsible for higher $\mathrm{NH}_{3}$ emission. All the probable sources were active during the pre-lockdown phase but emission started reducing after the Janta Curfew and during the countrywide lockdown.

Small-scale industries in Howrah accelerate pollution level and are responsible for high $\mathrm{SO}_{2}$ concentration (Fig. 11). The southern part has very minimum emission, but the northern, central, and north-western parts have recorded higher $\mathrm{SO}_{2}$ emission on 1 March. Concentration is moderately distributed in the northern part near Belur Math, RBU, and Ghusuri but all the parts have a sharp reduction in $\mathrm{SO}_{2}$ emission on 13 March (Fig. 11). Among the stations, Ghusuri has recorded high $\mathrm{SO}_{2}$ concentration on 1 March during the pre-lockdown phase with an amount of $67.39 \mu \mathrm{g} / \mathrm{m}^{3}$ as this part is highly industrialized, and industries like electronics, plastics, etc. which are considered under the 'red' category by WBPCB, 2018. The second highest concentration has been recorded at Belur Math with an amount of $24.45 \mu \mathrm{g} / \mathrm{m}^{3}$ as this particular area is considered as Belur Industrial Belt where manufacturing industries are very important. On 24 March and 7 April, only areas


Fig. 10 Spatio-temporal change of $\mathrm{NH}_{3}$ (2020) 



Fig. 11 Spatio-temporal change of $\mathrm{SO}_{2}(2020)$

near Belur Math and marginal eastern parts are recorded moderate $\mathrm{SO}_{2}$ emission and on 3 May, the $\mathrm{SO}_{2}$ emission has been flattened all over the study area as the most polluted sites noted the very minimum amount of $\mathrm{SO}_{2}$ concentration with an amount of $6.73 \mu \mathrm{g} / \mathrm{m}^{3}$ and $8.36 \mu \mathrm{g} / \mathrm{m}^{3}$ at Ghusuri and Belur Math, respectively, due shut down of all the industrial industries.

The concentration of $\mathrm{CO}$ is monitored on 8-hrs interval. Medium to high $\mathrm{CO}$ concentrations have been observed in KMC and HMC (Fig. 12). Vehicular emission contributes almost $90 \%$ of the total CO in the urban atmosphere (Jaffe 2012), and it has been found that the concentration of $\mathrm{CO}$ is $1.3-6.8$ times higher near the highly intensified vehicle zones than the urban periphery (Brice and Roesler 1966). It has a key role in controlling the oxidation processes of the atmosphere by performing as a sink for a larger fraction of the reactive hydroxyl radicals existing in the lower troposphere. The concentration of the gas


Fig. 12 Spatio-temporal change of CO (2020) 
in the urban atmosphere is highly controlled by the pattern of emission and spread of the gasoline by the motor vehicle (Jaffe 2012) and due to high vehicular emission and burning of woods and fossil fuel for cooking in residential areas and street-side shops. During the pre-lockdown period, Victoria with high traffic flow during the office hours, important traffic intersections which are Khidirpur Road, Acharya Jagadish Chandra Bose Road, Jawaharlal Nehru Road and Esplanade traffic intersection result in the highest $\mathrm{CO}$ concentration $\left(2.28 \mathrm{mg} / \mathrm{m}^{3}\right)$ and the lowest concentration has been recorded at Ballygunge $\left(0.72 \mathrm{mg} / \mathrm{m}^{3}\right)$ on 1 March. CO is released mainly from Kasba, Picnic Garden, Mullick Bazar, and Topsiais which is known for industrial activities that affect the neighbouring stations which are Victoria, FortWilliam, and Ballygunge (Datta et al. 2016). From 24 March, the day of lockdown, a mark reduction in $\mathrm{CO}$ concentration is noticed but a centre with relatively higher concentration is found near Victoria where the concentration reduced from 2.28 on 1 March to 0.64 on 3 May and this is the highest concentration among the other stations on that very particular day and later no such considerable changes have been observed.

The spatial pattern of ozone concentration is different from the other pollutants (Fig. 13). Ozone concentration is inversely related to $\mathrm{NH}_{3}(-0.63)$ and $\mathrm{NO}_{2}(-0.15)$, which is the reason for relatively higher concentration during the pre-lockdown phase and it can also be found from the correlation matrix (Fig. 15). The lowest concentration of $\mathrm{O}_{3}$ has been recorded at Jadavpur on 1 March $\left(20.15 \mu \mathrm{g} / \mathrm{m}^{3}\right)$, in contrast the $\mathrm{NO}_{2}$ and $\mathrm{NH}_{3}$ concentrations are $52.09 \mu \mathrm{g} / \mathrm{m}^{3}$ and $36.33 \mu \mathrm{g} / \mathrm{m}^{3}$, respectively. Here $\mathrm{NH}_{3}$ concentration is the second highest after Belur Math at Jadavpur supporting the significant inverse relationship between $\mathrm{NH}_{3}$ and $\mathrm{O}_{3}(-0.64)$. Another important station is Ghusuri where the second lowest $\mathrm{O}_{3}$ concentration has been recorded with $73.19 \mu \mathrm{g} / \mathrm{m}^{3}$ and $18.82 \mu \mathrm{g} / \mathrm{m}^{3}$ amount of $\mathrm{NO}_{2}$ and $\mathrm{NH}_{3}$ being recorded. The nearby Cossipore thermal power station near RBU is responsible for higher pollution and is also characterized by a high concentration of $\mathrm{PM}_{2.5}, \mathrm{PM}_{10}$, and $\mathrm{NO}_{2}$ as well on 1 March. Only the central Kolkata has recorded a higher $\mathrm{O}_{3}$ concentration near Victoria $\left(65.76 \mu \mathrm{g} / \mathrm{m}^{3}\right)$ and Rabindra Sarovar $\left(45.00 \mu \mathrm{g} / \mathrm{m}^{3}\right)$. The concentration of $\mathrm{O}_{3}$ is substantially reduced on 13 March 2020, the day of Janta Curfew because of the partial lockdown of $14 \mathrm{~h}$. On 24 March, the concentration has hiked all over the study area except two centres near RBU and Ballygunge. On 7 April, high concentration is recorded
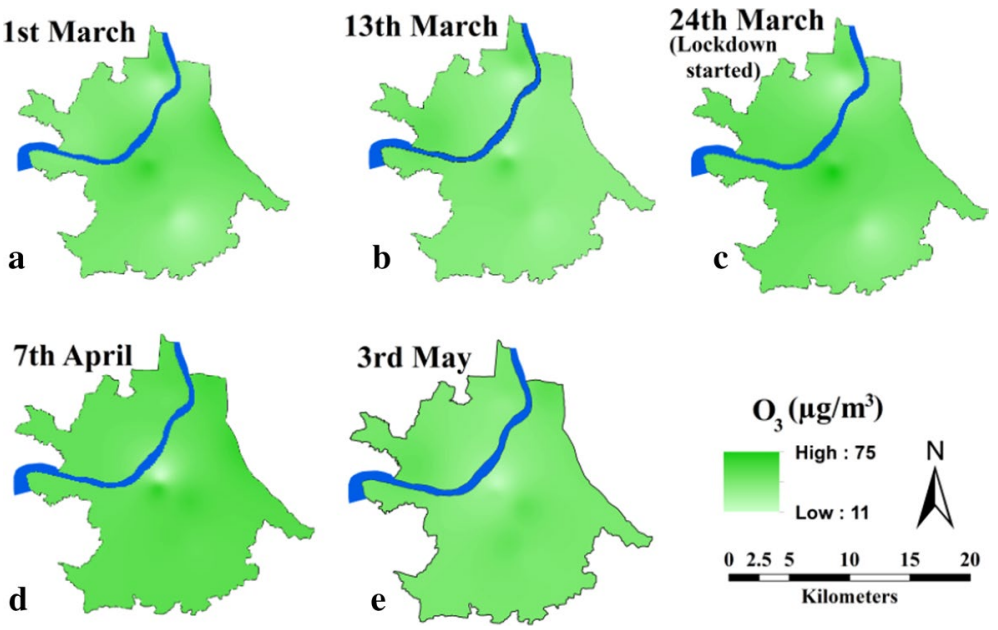

Fig. 13 Spatio-temporal change of $\mathrm{O}_{3}(2020)$ 
again and the areal extent is more than 24 march most importantly the hiking in the concentration in the northern part and Ballygunge adjoined areas because till 24 march, these parts have recorded minimum concentration continuously. After 24 march, the concentration has reduced remarkably and a relatively higher concentration has been recorded on 3 May, the relaxation in the lockdown in KMC and HMC results in this. The role of atmospheric chemistry is important here. The minimum concentration of other pollutants may result in the increase $\mathrm{O}_{3}$ concentration because hiking of $\mathrm{O}_{3}$ is caused by lower titration of $\mathrm{O}_{3}$ by $\mathrm{NO}$ due to the minimum emission of NOx from the vehicle (Sicard et al. 2020) and with a decreasing carbonaceous concentration increase the atmospheric visibility that promotes penetration of solar radiation favouring ozone formation (Zhang et al. 2019) that can be understood from the concentration pattern of $\mathrm{O}_{3}$. The highest concentration of $\mathrm{O}_{3}$ has been recorded at Rabindra Bharati $\left(53.66 \mu \mathrm{g} / \mathrm{m}^{3}\right)$, and very minimum concentration of $\mathrm{NO}_{2}\left(15.61 \mu \mathrm{g} / \mathrm{m}^{3}\right)$ and $\mathrm{NH}_{3}\left(22.52 \mu \mathrm{g} / \mathrm{m}^{3}\right)$ has been noted on 3 May. Particularly, this part of the study area suffers from severe vehicular emission (Chakrabartty and Gupta 2014) but during the lockdown period, the concentration of $\mathrm{NO}_{2}$ has been remarkably reduced.

AQI has fallen to 25 on 3 May from 325 on 1 march. In the map (Fig. 14), the higher concentration of the pollutants in the atmosphere is responsible for higher AQI and the opposite scenario can be observed during the lockdown period. Ballygunge followed by Ghusuri and Rabindra Bharati has recorded the highest AQI, and it can be noted as 304.31, 302.12, and 300.97 on 1 March during the pre-lockdown time which is considered as the 'poor' air quality and other stations have recoded moderate air quality. On 13 March, the pollution level has reduced half as the news of the COVID-19 spread and awareness started growing and major changes can be noticed on 24 March the day lockdown started just after the 14-h 'Janta Curfew' on 22 March. The levels of pollution have reduced almost six times for Ballygunge from 304.31 to only 50.29, from 302.12 to 78.87 in Ghusuri, and from 300.97 to 65.33 on 24 march as the restriction on human, and vehicular mobility was imposed as well as the effects of the Janta Curfew. Then after, this very little fluctuations can be noted for all the stations. A slight reduction in AQI and can be categorized under 'moderately polluted' on 13 March. On 24 March, air quality is improved to 'good' but a slight degradation can be observed on 7 April and then again the air quality has remarkably
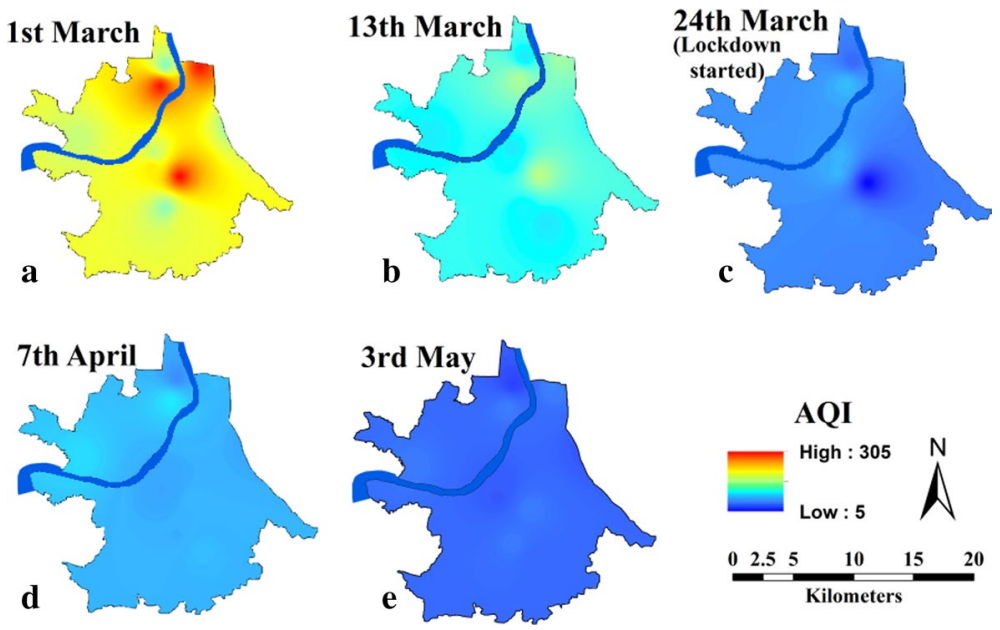

Fig. 14 Spatio-temporal change of AQI (2020) 
improved as the highest polluting sites started improving along with the moderately polluted stations like Jadavpur, Rabindra Sarovar, Victoria. On 3 may, the AQIs have been calculated for Ballygunge (51.67), Rabindra Bharati University (53.63), and Ghusri (52.01) and the results are the indication of 'good' air quality in KMC and HMC.

\subsection{Co-relationship between the ambient air pollutants}

To analyse the association among the pollutants, multiple correlation matrixes are conducted for pre-lockdown and during the lockdown phases (Fig. 15). In the diagram, the monochromatic red colour is showing positive correlations and the blue colour is representing the negative correlations. Different shades are used to show the intensity of relation. On the other hand, scatter plots are also showing the distributional pattern.

$\mathrm{PM}_{2.5}$ has a strong significant relationship with $\mathrm{PM}_{10}(r=0.99 *)$, this may be the result of almost the same sources of emission as previously discussed in the pre-lockdown phase, but later during the lockdown phase the correlation is also significant $\left(r=0.92^{*}\right)$ (Ibe et al. 2020). Due to the reduction in traffic congestion, the lockdown of industrial areas, the emission of these particulates also has reduced. $\mathrm{PM}_{2.5}$ is highly associated with $\mathrm{CO}$ and $\mathrm{NO}_{2}$ because the high concentration of both the pollutants is recorded near highly intensified traffic junction and industrial belts. During the lockdown period, the relations among the parameters have drastically changed which can be seen as correlations have taken a new dimension when there is a mark reduction in the concentration of pollutants. Almost the same phenomena can be observed for $\mathrm{PM}_{10}$ and these two particulate matters are the major sources of pollution in Kolkata (Das et al. 2015). Significantly moderate correlations have been traced out between $\mathrm{NH}_{3}$ and $\mathrm{NO}_{2}, \mathrm{PM}_{2.5}, \mathrm{PM}_{10}$, except these all the relations are insignificant during the pre-lockdown phase. But the correlations have become significant during the lockdown phase. $\mathrm{NH}_{3}$ has positive significant correlations with $\mathrm{PM}_{2.5}$ $\left(r=0.87^{*}\right), \mathrm{PM}_{10}\left(r=0.80^{*}\right), \mathrm{SO}_{2}\left(r=0.79^{*}\right), \mathrm{CO}\left(r=0.85^{*}\right)$ and $\mathrm{O}_{3}\left(r=0.73^{*}\right)$.

Sulphur dioxide is the precursor of acid rain as sulphuric acid in reaction with $\mathrm{H}_{2} \mathrm{O}$. Any significant correlation has not been established with $\mathrm{SO}_{2}$ with other pollutants except a



Fig. 15 Correlation among the pollutants during the $\mathbf{a}$ pre-lockdown and $\mathbf{b}$ during the lockdown period 
significant negative correlation ( $r=-0.31$ ) with $\mathrm{NH}_{3}$. According to chemists, any chemical reaction is not possible between these two pollutants except water (Guo et al. 2005). But the total scenario of $\mathrm{SO}_{2}$ has been changed during the lockdown period when there is a dropping down of pollutants concentration that results in the establishment of a significant correlation with $\mathrm{PM}_{2.5}\left(r=0.73^{*}\right), \mathrm{PM}_{10}(r=0.67 *), \mathrm{NH}_{3}(r=0.79 *), \mathrm{CO}\left(r=0.61^{*}\right)$, and $\mathrm{O}_{3}\left(r=0.73^{*}\right)$. A moderately significant correlation $\left(r=0.54^{*}\right)$ has been found between $\mathrm{SO}_{2}$ and ozone. The PL phase is characterized by higher SO2 concentration and relatively less concentration of ozone. Higher $\mathrm{SO}_{2}$ concentration accelerates ozone formation because of its role in the photochemical reaction that produces ozone in combination with NOx, VOC when insolation is higher. During the lockdown phase, a highly significant positive correlation $\left(r=0.73^{*}\right)$ has been found between these two components.

$\mathrm{CO}$ is only strongly correlated with $\mathrm{PM}_{2.5}\left(r=0.73^{*}\right), \mathrm{PM}_{10}\left(r=0.75^{*}\right)$, and $\mathrm{NO}_{2}$ $\left(r=0.77^{*}\right)$ in the pre-lockdown phase but during the lockdown phase, the relations have also established with other pollutants. The $\mathrm{OH}$ radicals which are formed due to chemical reactions in the upper atmosphere are very important in oxidizing (Harteck et al. 1998). CO also reacts with $\mathrm{O}_{3}$ (Jaffe 2012). The breakdown of ozone produces oxygen and the oxygen reacts with $\mathrm{CO}$ in the atmosphere through the reaction is not direct (Zhang et al. 2019).

In the pre-lockdown phase, $\mathrm{NH}_{3}$ and $\mathrm{O}_{3}$ have a significantly negative correlation $(r=-0.64 *)$ where the concentration of both the pollutants was high. Olszyna and Heicklen (1972) showed in an experiment that $\mathrm{O}_{3}$ is consumed and solid aerosol is formed very rapidly in reaction with $\mathrm{NH}_{3}$ but it is not reproducible. A high concentration of $\mathrm{NH}_{3}$ in the pre-lockdown phase and chemical reaction in the atmosphere reduces the amount of Ozone. On the other hand, during the lockdown period the correlation has a significant positive correlation $(\mathrm{r}=0.72 *)$ because the reaction is not possible when the amount is not significant (Olszyna and Heicklen 1972).

The processes which are related to the ozone formation are still not revealed so well and are still a challenge and need more studies (Monks et al. 2015). Ozone is also negatively correlated with $\mathrm{NO}_{2}$ in the urban atmosphere (Palmgren et al. 1996; Pires 2012; Wilby 2008). The photochemical production of ozone in the lower atmosphere (troposphere) is the result of the hydroxyl radical oxidation of carbon monoxide, methane, and non-methane hydrocarbons in the occurrence of nitrogen dioxide (Monks et al. 2015). In brief, ozone is produced depends mainly on the photolysis of nitrogen dioxide and the association of the photoproduct with $\mathrm{O}_{2}$ via a reaction (Monks et al. 2015; Pires 2012).

The reactions between these two components result in the degeneration and regeneration of ozone (Pires 2012). The high incursion of $\mathrm{NO}_{2}$ from the vehicle and industrial areas degrade ozone in the atmosphere by chemical reactions (Cox 2003). $\mathrm{NO}_{2}$ is broken down into NO that reacts with $\mathrm{O}_{3}$ in the presence of $\mathrm{UV}$, then again $\mathrm{NO}$ reacts with $\mathrm{O}_{3}$ and $\mathrm{NO}_{2}$ and $\mathrm{O}_{2}$ are the outcomes (Ebi and McGregor 2008). Colbeck and Harrison (1982) explained the relationship "If formaldehyde is photolysed, then

$$
\begin{gathered}
\mathrm{CH}_{2} \mathrm{O}+h v \rightarrow \mathrm{CHO}_{4}+\mathrm{H} \quad(\lambda<370 \mathrm{~nm}) \\
\mathrm{CHO}+\mathrm{O}_{2} \rightarrow \mathrm{HO}_{2}+\mathrm{CO} \\
\mathrm{HO}_{2}+\mathrm{NO} \rightarrow \mathrm{NO}_{2}+\mathrm{OH} \\
\mathrm{NO}_{2}+h v^{-} \rightarrow \mathrm{NO}+\mathrm{O}(3 \mathrm{P}) \quad(\lambda<420 \mathrm{~nm})
\end{gathered}
$$




$$
\mathrm{NO}+\mathrm{O}_{3}=\mathrm{NO}_{2}+\mathrm{O}_{2}
$$

The whole process continues all the time. This phenomenon is normal during the weekdays but during weekends $\mathrm{NO}_{2}$ concentration is reduced and $\mathrm{O}_{3}$ is increased in the urban atmosphere (Atkinson-Palombo et al. 2006); the lockdown has affected the emission in the same manner and to some extent more than that. A study by Cox (2003) showed that the area of ozone depletion is highly associated with $\mathrm{NO}_{2}$ emitting areas. From Fig. 15, it can be noticed that the $\mathrm{NO}_{2}$ and the $\mathrm{O}_{3}$ had a negative correlation in the pre-lockdown phase but later the relation has turned into a positive correlation because of the amount if $\mathrm{NO}_{2}$ is not considered for the reaction in the lower atmosphere, less amount of $\mathrm{NO}_{2}$ does not affect too much to the concentration of $\mathrm{O}_{3}$ (Pires 2012). In the lower atmosphere, particulate matters also act like sink so $\mathrm{PM}_{2.5}$ and $\mathrm{PM}_{10}$ concentration result in reducing the sink of hydroperoxy radicals and boosting the ozone concentration ( $\mathrm{Li}$ et al. 2019).

\subsection{Analysis of variance (ANOVA)}

ANOVA two-way has been used to understand the variance of means of air quality index AQI for all the stations (9) of both Kolkata and Howrah (Table 4). AQI is considered as the dependent variable and the period of pre-lockdown and during lockdown as the independent variables. After performing ANOVA two-way, it has been found that period (from pre-lockdown to during lockdown phase) has a very important role in reducing AQI, $F(1,611)=465.723, p<0.0001$ is a highly significant factor for the changing AQI. In changing AQI, the time has a $43.9 \%$ impact along with the stations having a $16.3 \%$ impact. If the time is constant, then the station is also significant and the interaction effect is significant at 0.0001 level with $F(8,611)=14.440, p<0.0001$. The effect of interaction on the AQI is also found significant $F(8,611)=6.045, p<0.0001$. Table 4 shows the pairwise comparisons within the station of AQI from the pre-lockdown phase to during the lockdown phase, and the mean difference within the station is highly significant with $p<0.0001$ of all the stations. Station Ballygunge, Kolkata, recorded the highest mean of 108.194 at $p<0.0001$ significant level between before lockdown and during the lockdown period, and on the other hand, Rabindra Sarovar, Kolkata, recorded a minimum mean difference of 45.735 with a significant level $p<0.0001$. The estimated mean differences of AQI between the lockdown period and the pre-lockdown period are considered for all the stations (Fig. 16). The air quality was 'poor' at Ballygunge, Rabindra Bharati University, and Ghusuri, but the air quality has remarkably improved in the lockdown period.

Table 4 Two-way ANOVA test for AQI based on stations and time. (Source: Computed by author)

\begin{tabular}{lcccr}
\hline Source & Sum of squares & $\begin{array}{l}\text { Degree of free- } \\
\text { dom }\end{array}$ & Mean squares & $F$ values \\
\hline Time & $779,793.621$ & 1 & $779,793.621$ & $465.723^{* *}$ \\
Station & $193,417.517$ & 8 & $24,177.190$ & $14.440^{* *}$ \\
Time * Station & $80,973.525$ & 8 & $10,121.691$ & $6.045^{* *}$ \\
Error & $994,577.145$ & 594 & 1674.372 & \\
Total & $6,860,202.710$ & 612 & & \\
\hline
\end{tabular}

**' $F$ ' significant at $p<0.01$ 


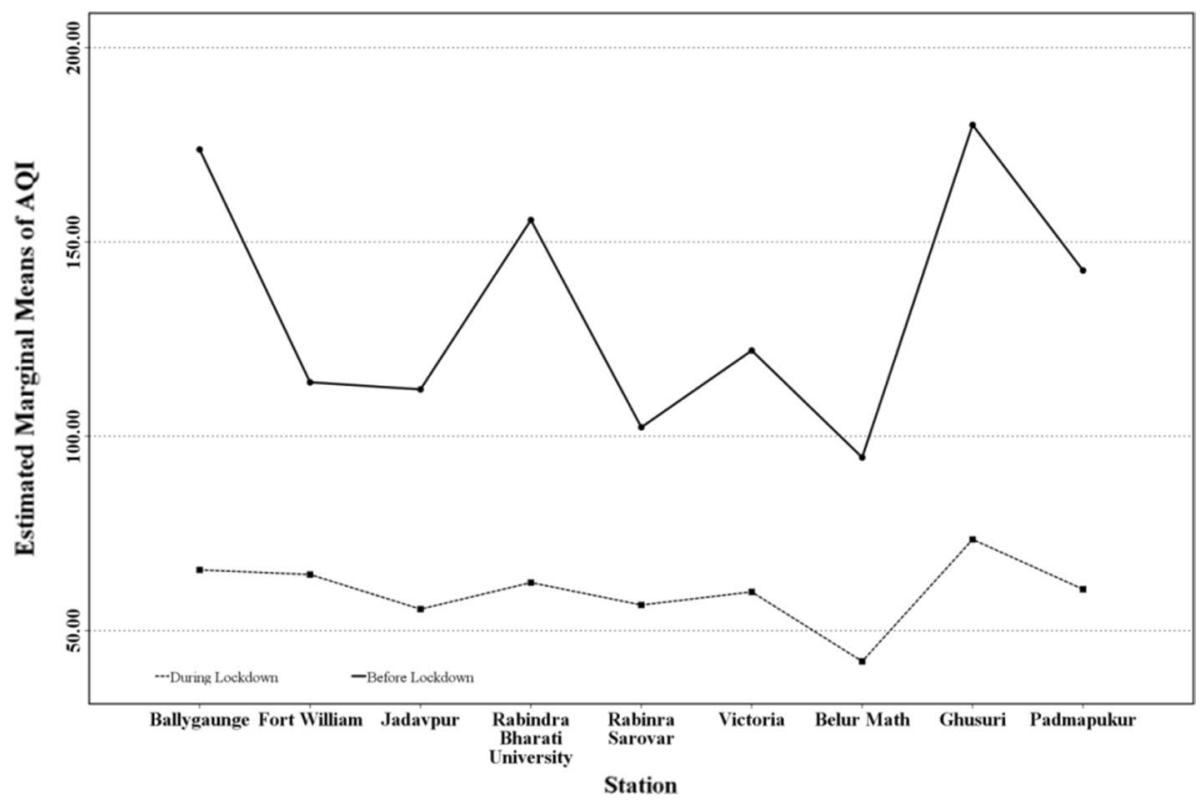

Fig. 16 Mean difference of each station between the pre-lockdown and during lockdown

\section{Conclusion}

The study has been yielded with a significant outcome that the lockdown has remarkably reduced the pollution level and air quality has improved from the 'poor' category to the 'good' category from the pre-lockdown period to during the lockdown period in KMC and HMC. $\mathrm{PM}_{2.5}$ and $\mathrm{PM}_{10}$ are responsible for pollution in KMC and HMC though the belowpermissible-level concentration of $\mathrm{NO}_{2}$ has been recorded in both the municipal corporations, it is a very important pollutant and has reduced specifically during the lockdown. In the northern part of KMC near RBU due to the continuation of thermal power production, the pollution level is relatively higher and the other two important centres, Ghusuri and Ballygunge, are worst affected by small-scale industries and after the lockdown, the pollution level has flattened. The relationships among the pollutants have also transformed with the changing magnitude of the pollutants as during the pre-lockdown phase, the some significant and some insignificant relationships have been found but during the lockdown phase, all the relationships have become very significant. Most interestingly, the concentration of $\mathrm{O}_{3}$ increased after the imposition lockdown as it is related inversely with $\mathrm{NH}_{3}$ and $\mathrm{NO}_{2}$.

The major pollutants are $\mathrm{PM}_{2.5}, \mathrm{PM}_{10}$, and $\mathrm{NO}_{2}$ and have markedly condensed from prelockdown to during the lockdown period. The Cossipore thermal power station, small-scale industrial hubs, and traffic are the main sources of pollution, but the imposition of lockdown all over the country has resulted in a quick fall in the concentration of pollutants. Implementations of lockdown at this temporal and regional scale are not possible, but the situation has proved that the recovery of the environment is very rapid when human interventions are very less. 
Acknowledgments Especially acknowledged to the editor and reviewers for their immense contribution to the improvement of this article. The authors acknowledge the NASA Giovanni and Earth null school for the free use of pollutant data and maps. We acknowledge the CPCB online portal to provide the data free of cost. We are thankful to Aparupa Sinha, Satyajit Paul, and Sukanya Das for their immense contribution to improving the literature. We also want to express our sincere gratitude to the anonymous reviews and editors for their comments which contributed to the improvement of the paper.

Author contributions Mohan Sarkar contributed to conceptualization, methodology, software, formal analysis, visualization, and writing-original draft. Anupam Das contributed to conceptualization, methodology, investigation, validation, data curation, visualization, writing-review, and editing. Sutapa Mukhopadhyay contributed to visualization, writing-review and editing, and supervision.

Funding No funding.

Availability of data Data are collected from CPCB online portal for pollutants (https://app.cpcbccr.com/ ccr/\#/caaqm-dashboard-all/caaqm-landing) and images of $\mathrm{NO}_{2}$ are downloaded from NASA GIOVANNI (https://giovanni.gsfc.nasa.gov/giovanni/) to compare the change and also from Earth nullschool (https:// earth.nullschool.net/)to compare the yearly variability in the concentration of $\mathrm{PM}_{2.5}$ and $\mathrm{PM}_{10}$.

Code availability MS office 2007, STATA 12, JMP 15, IBM SPSS version 23, ArcGIS 10.3.

\section{Compliance with ethical standards}

Conflict of interest Authors have no conflict of interest.

\section{References}

Abdul Halim, N. D., Latif, M. T., Ahamad, F., Dominick, D., Chung, J. X., Juneng, L., et al. (2018). The long-term assessment of air quality on an island in Malaysia. Heliyon, 4(12), e01054. https://doi. org/10.1016/j.heliyon.2018.e01054.

Aneja, V. P., Agarwal, A., Roelle, P. A., Phillips, S. B., Tong, Q., Watkins, N., et al. (2001). Measurements and analysis of criteria pollutants in New Delhi, India. Environment International, 27(1), 35-42. https ://doi.org/10.1016/S0160-4120(01)00051-4.

Arbilla, G., Martins, E. M., Moreira, A., \& Moreira, L. F. R. (2002). Ozone air quality modelling. A case study: A heavily vehicle impacted urban avenue in Rio de Janeiro, Brazil. Journal of the Brazilian Chemical Society, 13(3), 308-317. https://doi.org/10.1590/S0103-50532002000300004.

Ashhar, M. M., Akram, A., \& Hussain, A. (2007). Ambient air quality monitoring of Aligarh City: A case study. The International Journal of Environmental, Cultural, Economic \& Social Sustainability, 3(2007), 6-14.

Atkinson-Palombo, C. M., Miller, J. A., \& Balling, R. C., Jr. (2006). Quantifying the ozone "weekend effect" at various locations in Phoenix. Arizona, 40(39), 7644-7658. https://doi.org/10.1016/j.atmos env.2006.05.023.

Berman, J. D., \& Ebisu, K. (2020). Changes in U.S. air pollution during the COVID-19 pandemic. The Science of the Total Environment, 739, 139864. https://doi.org/10.1016/j.scitotenv.2020.139864.

Bhattacharjee, Y. (2008). Choking on fumes, Kolkata faces a noxious future. Science (New York, N.Y.), 319(5864), 749. https://doi.org/10.1126/science.319.5864.749.

Brice, R. M., \& Roesler, J. F. (1966). The exposure to carbon monoxide of occupants of vehicles moving in heavy traffic. Journal of the Air Pollution Control Association, 16(11), 597-600. https://doi. org/10.1080/00022470.1966.10468521.

Carmichael, G. R., Ferm, M., Thongboonchoo, N., Woo, J. H., Chan, L. Y., Murano, K., et al. (2003). Measurements of sulfur dioxide, ozone and ammonia concentrations in Asia, Africa, and South America using passive samplers. Atmospheric Environment, 37(9-10), 1293-1308. https://doi.org/10.1016/ S1352-2310(02)01009-9.

Census of India. (2011). West Bengal series-20 Part XII-B District census handbook Kolkata village and town wise primary census abstract (PCA). Directorate of Census Operations West Bengal.

Chakrabartty, A., \& Gupta, S. (2014). Traffic Congestion in the Metropolitan City of Kolkata. Journal of Infrastructure Development, 6(1), 43-59. https://doi.org/10.1177/0974930614543046. 
Chaurasia, S., Dwivedi, P., Singh, R., Gupta, A. D. (2013). Assessment of ambient air quality status and air quality index of Bhopal city (Madhya Pradesh), India. International Journal of Current Science, 9(2013), 96-101.

Chowdhury, I. R. (2015). Scenario of vehicular emissions and its effect on human health in Kolkata city. International Journal of Humanities and Social Science Invention, 4(5), 1-9.

Cole, M. A., Elliott, R. J. R., \& Liu, B. (2020). The impact of the Wuhan Covid-19 lockdown on air pollution and health: A machine learning and augmented synthetic control approach. Discussion papers.

Colbeck, I., Harrison, M. R. (1982). Tropospheric Ozone. In Environmental Chemistry (pp. 1-48). The Royal Society of Chemistry.

Collivignarelli, M. C., Abbà, A., Bertanza, G., Pedrazzani, R., Ricciardi, P., \& Carnevale Miino, M. (2020). Lockdown for CoViD-2019 in Milan: What are the effects on air quality? Science of the Total Environment, 732, 139280. https://doi.org/10.1016/j.scitotenv.2020.139280.

Cox, R. M. (2003). The use of passive sampling to monitor forest exposure to $\mathrm{O}_{3}, \mathrm{NO}_{2}$ and $\mathrm{SO}_{2}: \mathrm{A}$ review and some case studies. Environmental Pollution, 126(3), 301-311. https://doi.org/10.1016/ S0269-7491(03)00243-4

CPCB. (2014). National Air Quality Index. Central Pollution Control Board, Minstry of Environment, Forest and Climate Change, Government of India; Delhi, India.

Dadhich, A. P., Goyal, R., \& Dadhich, P. N. (2018). Assessment of spatio-temporal variations in air quality of Jaipur city, Rajasthan, India. Egyptian Journal of Remote Sensing and Space Science, 21(2), 173-181. https://doi.org/10.1016/j.ejrs.2017.04.002.

Das, R., Khezri, B., Srivastava, B., Datta, S., Sikdar, P. K., Webster, R. D., et al. (2015). Trace element composition of $\mathrm{PM}_{2.5}$ and $\mathrm{PM}_{10}$ from Kolkata-A heavily polluted Indian metropolis. Atmospheric Pollution Research, 6(5), 742-750. https://doi.org/10.5094/APR.2015.083.

Datta, M., Barman, M., \& Manna, S. (2016). Living-dagerously-kolkata-hotspots.pdf. Toxics Links.

David, N., Pérez-Arribas L. V., Manzoor S, \& Jorge, O. C. (2019). Statistical tools for air pollution assessment: multivariate and spatial analysis studies in the Madrid region.

Debnath, J., Majumder, D., \& Biswas, A. (2018). Air quality assessment using weighted interval type-2 fuzzy inference system. Ecological Informatics, 46, 133-146. https://doi.org/10.1016/j.ecoin f.2018.06.002.

Ebi, K. L., \& McGregor, G. (2008). Climate change, tropospheric ozone and particulate matter, and health impacts. Environmental Health Perspectives, 116(11), 1449-1455. https://doi.org/10.1289/ ehp. 11463.

Fan, C., Li, Y., Guang, J., Li, Z., Elnashar, A., Allam, M., et al. (2020). The impact of the control measures during the COVID-19 outbreak on air pollution in China. Remote Sensing, 12(10), 1613. https ://doi.org/10.3390/rs12101613.

Fenn, M. E., Bytnerowicz, A., Schilling, S. L., Vallano, D. M., Zavaleta, E. S., Weiss, S. B., et al. (2018). On-road emissions of ammonia: An underappreciated source of atmospheric nitrogen deposition. Science of the Total Environment, 625, 909-919. https://doi.org/10.1016/j.scitotenv.2017.12.313.

Fernandes, N. (2020). Economic effects of coronavirus outbreak (COVID-19) on the world economy. SSRN Electronic Journal. https://doi.org/10.2139/ssrn.3557504.

Figueiredo, A., Codina, A., Moreira, D., Figueiredo, M., Saez, M., \& León, A. (2020). Impact of lockdown on COVID-19 incidence and mortality in China: An interrupted time series study. WHO Bulletin. https://doi.org/10.2471/BLT.20.251561.

Garg, A., Shukla, P. R., Bhattacharya, S., Dadhwal, V. K. (2001). Sub-region (district) and sector level $\mathrm{SO} 2$ and $\mathrm{NO}(\mathrm{x})$ emissions for India: Assessment of inventories and mitigation flexibility. Atmospheric Environment, 35(4), 703-713.

Gaur, A., Tripathi, S. N., Kanawade, V. P., Tare, V., \& Shukla, S. P. (2014). Four-year measurements of trace gases $\left(\mathrm{SO}_{2}, \mathrm{NO}_{\mathrm{x}}, \mathrm{CO}\right.$, and $\left.\mathrm{O}_{3}\right)$ at an urban location, Kanpur, Northern India. Journal of Atmospheric Chemistry, 71(4), 283-301. https://doi.org/10.1007/s10874-014-9295-8.

Gautam, S. (2020). The influence of COVID-19 on air quality in India: A boon or inutile. Bulletin of Environmental Contamination and Toxicology, 104(6), 724-726. https://doi.org/10.1007/s0012 8-020-02877-y.

Ghose, M. K., Paul, R., \& Banerjee, S. K. (2004). Assessment of the impacts of vehicular emissions on urban air quality and its management in Indian context: The case of Kolkata (Calcutta). Environmental Science and Policy, 7(4), 345-351. https://doi.org/10.1016/j.envsci.2004.05.004.

Ghose, M. K., Paul, R., \& Banerjee, S. K. (2005). Assessment of the impact on human health of exposure to urban air pollutants: An Indian case study. International Journal of Environmental Studies, 62(2), 201-214. https://doi.org/10.1080/0020723042000275123. 
GOI. (2020). Detail question and answers on COVID-19 for Public. Govt of India. Retrieved from 4 May, 2020 from https://www.mohfw.gov.in/pdf/MindingourmindsduringCoronaeditedat.pdf.

Goverment of West Bengal. (2019). Comprehensive air quality action plan for Kolkata (Vol. 2018).

Guo, Y., Liu, Z., Huang, Z., Liu, Q., \& Guo, S. (2005). Reaction behavior of sulfur dioxide with ammonia. AmericanChemical Society, 44, 9989-9995. https://doi.org/10.1021/ie050734q.

Gupta, A. K., Karar, K., Ayoob, S., \& John, K. (2008). Spatio-temporal characteristics of gaseous and particulate pollutants in an urban region of Kolkata, India. Atmospheric Research, 87(2), 103-115. https:// doi.org/10.1016/j.atmosres.2007.07.008.

Harteck, P., Dondes, S., \& Reaction, T. M. (1998). Reaction of Carbon Monoxide and Ozone. 1734(1957). https://doi.org/10.1063/1.1743612.

Haque, M. S., \& Singh, R. B. (2017). Air pollution and human health in Kolkata, India: A case study. Climate, 5(4), 1-16. https://doi.org/10.3390/cli5040077.

He, G., Pan, Y., \& Tanaka, T. (2020). COVID-19, city lockdown, and air pollution: Evidence from China. medRxiv, 2020.03.29.20046649. https://doi.org/https://doi.org/10.1101/2020.03.29.20046649

Ibe, F. C., Opara, A. I., Duru, C. E., Obinna, I. B., \& Enedoh, M. C. (2020). Statistical analysis of atmospheric pollutant concentrations in parts of Imo State. Southeastern Nigeria. Scientific African, 7 , e00237. https://doi.org/10.1016/j.sciaf.2019.e00237.

Jaffe, L. S. (2012). Ambient carbon monoxide and its fate in the atmosphere. Journal of the Air Pollution Control Association. https://doi.org/10.1080/00022470.1968.10469168.

Joshi, P. C., \& Mahadev, S. (2011). Distribution of air pollutants in ambient air of district Haridwar (Uttarakhand), India: A case study after establishment of State Industrial Development Corporation. International Journal of Environmental Sciences, 2(1), 249-270. https://doi.org/10.6088/ijes.00202010026.

Jumaah, H. J., Ameen, M. H., Kalantar, B., Rizeei, H. M., \& Jumaah, S. J. (2019). Air quality index prediction using IDW geostatistical technique and OLS-based GIS technique in Kuala Lumpur, Malaysia. Geomatics, Natural Hazards and Risk, 10(1), 2185-2199. https://doi.org/10.1080/19475 705.2019.1683084.

Karar, K., Gupta, A. K., Kumar, A., \& Biswas, A. K. (2006). Characterization and identification of the sources of chromium, zinc, lead, cadmium, nickel, manganese and Iron in PM10 particulates at the two sites of Kolkata, India. Environmental Monitoring and Assessment, 120(1-3), 347-360. https:// doi.org/10.1007/s10661-005-9067-7.

Kazimuddin, A., \& Banerjee, L. (2015). FIGHTING FOR AIR. Down To Earth. Retrieved August 10, 2020, from https://www.downtoearth.org.in/coverage/energy/a-renewable-crisis-18783.

Kerimray, A., Baimatova, N., Ibragimova, O. P., Bukenov, B., Kenessov, B., Plotitsyn, P., et al. (2020). Assessing air quality changes in large cities during COVID-19 lockdowns: The impacts of traffic-free urban conditions in Almaty, Kazakhstan. Science of the Total Environment, 730, 139179. https://doi. org/10.1016/j.scitotenv.2020.139179.

Kolkata most polluted metro; India has highest PAH level, says Tokyo University study—The Financial Express. (2020). Retrieved June 15, 2020, from https://www.financialexpress.com/economy/kolkatamost-polluted-metro-india-has-highest-pah-level-says-tokyo-university-study/3982/.

Kumar, S. D., \& Dash, A. (2018). Seasonal variation of air quality index and assessment. Global Journal of Environmental Science and Management, 4(4), 483-492. https://doi.org/10.22034/gjesm.2018.04.008.

Leighton, A. P. (1962). Photochemistry of Air Pollution-1st Edition. Retrieved June 7, 2020, from https:// www.elsevier.com/books/photochemistry-of-air-pollution/leighton/978-0-12-442250-6.

Li, K., Jacob, D. J., Liao, H., Shen, L., Zhang, Q., \& Bates, K. H. (2019). Anthropogenic drivers of 20132017 trends in summer surface ozone in China. Proceedings of the National Academy of Sciences of the United States of America, 116(2), 422-427. https://doi.org/10.1073/pnas.1812168116.

Lu, H., Stratton, C. W., \& Tang, Y. W. (2020). Outbreak of pneumonia of unknown etiology in Wuhan, China: The mystery and the miracle. Journal of Medical Virology, 92(4), 401-402. https://doi. org/10.1002/jmv.25678.

Mahato, S., Pal, S., \& Ghosh, K. G. (2020). Science of the total environment effect of lockdown amid COVID-19 pandemic on air quality of the megacity Delhi, India. Science of the Total Environment, 730, 139086. https://doi.org/10.1016/j.scitotenv.2020.139086.

Méndez-Arriaga, F. (2020). The temperature and regional climate effects on communitarian COVID-19 contagion in Mexico throughout phase 1. Science of the Total Environment, 735, 139560. https://doi. org/10.1016/j.scitotenv.2020.139560.

Mondal, R., Sen, G. K., Chatterjee, M., Sen, B. K., \& Sen, S. (2000). Ground-level concentration of nitrogen oxides $(\mathrm{NO}(\mathrm{x}))$ at some traffic intersection points in Calcutta. Atmospheric Environment, 34(4), 629-633. https://doi.org/10.1016/S1352-2310(99)00216-2. 
Monks, P. S., Archibald, A. T., Colette, A., Cooper, O., Coyle, M., Derwent, R., et al. (2015). Tropospheric ozone and its precursors from the urban to the global scale from air quality to short-lived climate forcer. Atmospheric Chemistry and Physics, 15(15), 8889-8973. https://doi.org/10.5194/acp-15-8889-2015.

Mukherjee, A., Mukherjee, G., Banerjp, U., \& Muichopadryay, S. P. (1998). Occupational exposure of the traffic, personnel of Calcutta to lead and carbon monoxide. Pollution Research, 17, 359-362.

Nakada, L. Y. K., \& Urban, R. C. (2020). COVID-19 pandemic: Impacts on the air quality during the partial lockdown in São Paulo state, Brazil. Science of the Total Environment, 730, 139087. https://doi. org/10.1016/j.scitotenv.2020.139087.

Nandi, S. (2017). 5 Worst Traffic Choke Points all across Kolkata City. Retrieveed August 27, 2020, from https://www.whatsuplife.in/kolkata/blog/worst-traffic-congestion-choke-points-kolkata.

Njoku, P., Ibe, F. C., Alinnor, J., \& Opara, A. I. (2016). Seasonal variability of carbon monoxide (CO) in the ambient environment of IMO state, Nigeria. International Letters of Natural Sciences, 53, 40-52. https ://doi.org/10.18052/www.scipress.com/ilns.53.40.

Olszyna, J. K., \& Heicklen, J. (1972). The reaction of ozone with Ammonia. Journal of Physical Chemistry, 70(2), 191-210. https://doi.org/10.1021/j100874a025.

Otmani, A., Benchrif, A., Tahri, M., Bounakhla, M., Chakir, E. M., El Bouch, M., et al. (2020). Impact of Covid-19 lockdown on $\mathrm{PM}_{10}, \mathrm{SO}_{2}$ and $\mathrm{NO}_{2}$ concentrations in Salé City (Morocco). Science of the Total Environment, 735(2), 139541. https://doi.org/10.1016/j.scitotenv.2020.139541.

Palmgren, F., Berkowicz, R., Hertel, O., \& Vignati, E. (1996). Effects of reduction of NO(x) on the $\mathrm{NO}_{2}$ levels in urban streets. Science of the Total Environment, 189-190(96), 409-415. https://doi. org/10.1016/0048-9697(96)05238-2.

Pires, J. C. M. (2012). Ozone weekend effect analysis in three European urban areas. Clean-Soil, Air, Water, 40(8), 790-797. https://doi.org/10.1002/clen.201100410.

Poshtmasari, H. K., Sarvestani, Z. T., Kamkar, B., Shataei, S., \& Sadeghi, S. (2012). Comparison of interpolation methods for estimating $\mathrm{pH}$ and $\mathrm{EC}$ in agricultural fields of Golestan Province. International Journal of Agriculture and Crop Sciences, 4(4), 157-167.

Pulikesi, M., Baskaralingam, P., Rayudu, V. N., Elango, D., Ramamurthi, V., \& Sivanesan, S. (2006). Surface ozone measurements at urban coastal site Chennai, India. Journal of Hazardous Materials, 137(3), 1554-1559. https://doi.org/10.1016/j.jhazmat.2006.04.040.

Roy, S. S., Singh, R. B., \& Kumar, M. (2015). An analysis of local spatial temperature patterns in the Delhi metropolitan area. Physical Geography. https://doi.org/10.2747/0272-3646.32.2.114.

Sicard, P., De Marco, A., Agathokleous, E., Feng, Z., Xu, X., Paoletti, E., et al. (2020). Amplified ozone pollution in cities during the COVID-19 lockdown. Science of the Total Environment, 735, 139542. https://doi.org/10.1016/j.scitotenv.2020.139542.

Sikarwar, A., \& Rani, R. (2020). Assessing the immediate effect of COVID-19 lockdown on air quality: A case study of Delhi, India (pp. 1-19).

Song, J., Guang, W., Li, L., \& Xiang, R. (2016). Assessment of air quality status in Wuhan, Chian. Atmosphere, 7(4), 56. https://doi.org/10.3390/atmos7040056.

Spiroska, J., Rahman, A., \& Pal, S. (2013). Air pollution in Kolkata: An analysis of current status and interrelation between different factors. South East European University Review, 8(1), 182-214. https://doi. org/10.2478/v10306-012-0012-7.

Srivastava, S., Kumar, A., Bauddh, K., Gautam, A. S., \& Kumar, S. (2020). 21-day lockdown in india dramatically reduced air pollution indices in Lucknow and New Delhi, India. Bulletin of Environmental Contamination and Toxicology. https://doi.org/10.1007/s00128-020-02895-w.

The Economics Times. (2020). India news: India observes Janata curfew, millions stay indoors-The Economic Times. Retrieved June 15, 2020, from https://economictimes.indiatimes.com/news/politics-andnation/india-observes-janata-curfew-millions-stay-indoors/articleshow/74756225.cms.

Tobías, A., Carnerero, C., Reche, C., Massagué, J., Via, M., Minguillón, M. C., et al. (2020). Changes in air quality during the lockdown in Barcelona (Spain) one month into the SARS-CoV-2 epidemic. Science of the Total Environment, 726, 138540. https://doi.org/10.1016/j.scitotenv.2020.138540.

Upadhyay, A., Kanchan, Goyal, P. G., Yerramilli, A., \& Gorai, A. K. (2014). Development of a fuzzy pattern recognition model for air quality assessment of Howrah City. Aerosol and Air Quality Research, 14(6), 1639-1652. https://doi.org/10.4209/aaqr.2013.04.0118.

Wang, Q., \& Su, M. (2020). A preliminary assessment of the impact of COVID-19 on environment-A case study of China. Science of the Total Environment, 728, 138915. https://doi.org/10.1016/j.scito tenv.2020.138915.

Wang, T., Ding, A., Gao, J., \& Wu, W. S. (2006). Strong ozone production in urban plumes from Beijing, Chian. Geophysical Research Letters, 33(21), 1-5. https://doi.org/10.1029/2006GL027689.

West Bengal Pollution Control Board. (1981). West Bengal pollution (Vol. 10, pp. 4-5). 
Wilby, R. L. (2008). Constructing climate change scenarios of urban heat island intensity and air quality. Environment and Planning B: Planning and Design, 35(5), 902-919. https://doi.org/10.1068/b33066t.

Zambrano-monserrate, M. A., Alejandra, M., \& Sanchez-alcalde, L. (2020). Science of the total environment indirect effects of COVID-19 on the environment. Science of the Total Environment, 728, 138813. https://doi.org/10.1016/j.scitotenv.2020.138813.

Zhang, J. J., Wei, Y., \& Fang, Z. (2019). Ozone pollution: A major health hazard worldwide. Frontiers in Immunology, 10, 1-10. https://doi.org/10.3389/fimmu.2019.02518.

Publisher's Note Springer Nature remains neutral with regard to jurisdictional claims in published maps and institutional affiliations. 